\title{
Norfloxacin-tenoxicam dual drug delivery system based on poly(lactic acid) microspheres and electrospun fibers: Release and in vivo study
}

\author{
Nehal Salahuddin ${ }^{\circledR}$, Mohamed Gaber ${ }^{(}$, Sahar Elneanaey, Mohamed Ahmed Abdelwahab ${ }^{*}$ \\ Chemistry Department, Faculty of Science, Tanta University, 31527 Tanta, Egypt
}

Received 13 August 2021; accepted in revised form 15 November 2021

\begin{abstract}
This study presents a new dual drug delivery system (DDDS) of poly(lactic acid) (PLA) with different morphologies (spheres and fibers). One approach for delivering Norfloxacin-Tenoxicam (NOR-TENO) drugs based on PLA microspheres was prepared by encapsulating TENO into PLA via emulsion-evaporation method to form TENO/microspheres then NOR was then adsorbed onto the surface of these microspheres by loading process. Another approach was designed by integrating a mixture of NOR-TENO drugs into the PLA matrix, then through the electrospinning process; NOR-TENO/electrospun fibers were fabricated. The microspheres and electrospun fibers had been characterized through FTIR, XRD, and SEM. Release behaviors of NOR-TENO were determined at $\mathrm{pH}(5.4,6.7$ and 7.4), where the release of the two drugs was faster in the two systems at $\mathrm{pH}$ 7.4. Antimicrobial activity of NOR-TENO/microspheres and NOR-TENO/electrospun fibers against $S$. aureus, $B$. cereus, and E. coli bacteria was examined in vitro, and NOR-TENO/electrospun fibers have better potential in killing bacteria. In vitro cytotoxicity assay of NOR-TENO/microspheres against HepG2, MCF-7, and HCT116 tumor cells were tested, and NOR-TENO/microspheres was highly cytotoxic to MCF-7 cells $\left(I C_{50}=21.87 \mu \mathrm{g} \cdot \mathrm{ml}^{-1}\right)$ with the lowest cytotoxic effect on WI-38 normal cells (the half maximal inhibitory concentration $I C_{50}=58.12 \mu \mathrm{g} \cdot \mathrm{ml}^{-1}$ ). In vivo study of DMBA-induced breast cancer in rats had been accomplished for NOR-TENO/microspheres, which offer promising results in breast cancer treatment.
\end{abstract}

Keywords: nanomaterials, biodegradable polymers, biocompatible polymers, electrospun fibers, microspheres

\section{Introduction}

A drug delivery system (DDS) is a formulation or device that enables the drug to reach its site of action, which can achieve the desired therapeutic effect without fluctuation in drug concentration and dose not require single and frequent administration [1]. A dual DDS (DDDS) refers to two different delivered to the targeted sites to control the release of each drug. Because of the complexity of the pathology, multidrug resistance, and ineffective cell uptake, combination therapy and the effective co- or tri-delivery of drugs to tumor cells are the main solution in the tumor treatment [1]. Drug delivery strategies can induce synergistic effects in vivo and in vitro; thus, the ideal nanoformulation combination therapy can offer some advantages, for example, long cycle time, controlled release curve, low side effects, and high anti-cancer effect [1].

Norfloxacin (NOR), the second generation of fluoroquinolones, is a synthetic chemotherapeutic antibacterial agent [2]. NOR works by inhibiting numerous types of bacterial enzymes by controlling the topology of DNA and is essential for chromosome function and replication [3]. Barman et al. [4] developed halloysite/chitosan nanocomposites for NOR delivery with $31 \%$ release within $6 \mathrm{hrs}$ with an effective

\footnotetext{
${ }^{*}$ Corresponding author, e-mail: mohamed.abdelwahab@science.tanta.edu.eg
} (C) BME-PT 
antibacterial action against $S$. aureus and E. coli. Many studies have focused on the conversion of the quinolone family from antibacterial agents to antitumor agents. This drug family shows not only high activity on bacterial topoisomerase but also high activity on eukaryotic topoisomerase, and it has a toxic effect on cultured mammalian cells and tumor models in vivo [5]. The effectiveness of fluoroquinolones in inhibiting the tumor cells' growth in vivo and in vitro makes them a double-edged sword. For example, ciprofloxacin was used in clinical trials for bladder cancer therapy and acute myeloid leukemia [6]. Salahuddin et al. [7] designed an extended-release formulation of NOR up to $1080 \mathrm{hrs}$ with $90 \%$ dug release based on $\mathrm{TiO}_{2} /$ (polylactic acid) (PLA), where $\mathrm{PLA} / \mathrm{NOR}$ with $5 \% \mathrm{TiO}_{2}$ formulation introduced a high cytotoxic effect on MCF-7, HepG2, HCT116, PC-3, and Hela tumor cell lines with moderate cytotoxicity to WI-38 normal cell lines.

Tenoxicam (TENO), a non-steroidal anti-inflammatory drug, has potent effects as anti-inflammatory, antipyretic, and analgesia [8]. TENO acts by inhibiting prostaglandin synthesis by inhibiting cyclooxygenase enzymes (membrane-associated proteins) that catalyze the formation of cyclic endoperoxides from arachidonic acid that is a dietary fatty acid [9]. Vagare [10] was evaluated the colon-specific DDS of Tenoxicam coated by hydroxypropyl methylcellulose mixed with guar gum which modifies drug release through releasing the effective drug amount to the colon and the lowest drug amount in the small intestine and stomach. Non-steroidal anti-inflammatory drugs (NSAIDs) are utilized as analgesic agents and anti-inflammatory. Moreover, NSAIDs have chemosuppressive and chemopreventive effects on numerous tumor cell lines [11]. Many studies in the last years have shown that different NSAIDs, such as meloxicam and piroxicam, have antitumor, chemosuppressive, and chemopreventive effects on several types of tumor cell lines and animal models [12]. Tamasi et al. [13] synthesized a new platinum complex containing anti-inflammatory drugs meloxicam (H2MEL) and isoxicam (H2ISO). Oxicam molecule was partially released into free ligands and living tissues, and coordination residues worked together to fight cancer and inflammation. Some complexes have high cytotoxicity on $\mathrm{CH} 1$ cells (ovarian cancer) and HeLa cells (cervical cancer) and moderate cytotoxicity on human SW480 (colon cancer) and U2-OS cells (osteosarcoma) in vitro.
Biodegradable polymers are mainly used in DDSs to overcome challenges associated with stability and preferred drug release profiles [14]. PLA has excellent potential in the development of DDSs due to its ideal biocompatibility, and biodegradability, and has been accepted by the FDA (Food and Drug Administration) for clinical use [15]. The use of PLA as a drug carrier has many advantages, such as localized drug delivery, extended drug delivery, drug stability, and the release rate is less dependent on drug characteristics with a constant release rate over time [16]. PLA has been used as a favorable polymer for various forms of DDSs [17], including hydrogels, microspheres, nanoparticles, scaffolds, and electrospun fibers. PLA microspheres have the characteristics of large surface area and can be used for drug delivery, cell culture, tissue engineering scaffolds, etc. [18]. Cao et al. [19] prepared PLA microspheres encapsulated 5-fluorouracil through solvent evaporation method. The release profile of 5-FU from the microspheres displayed an initial burst release and then slowly released within 10 days. Deepikaa et al. [20] used a water/oil/water emulsion method to prepare PLGA microspheres loaded with a mixture of benzamide at (B) and rutin (R) drugs. They revealed that drugs/PLGA exhibited a higher toxic effect on cancer cells without an effect on healthy cells. The cumulative release of $\mathrm{R}$ and $\mathrm{B}$ drugs was $85.62,60.50$, $55.80 \%$, and $78.66,55.88$, and $51.50 \%$ at $\mathrm{pH}=5.5$, 6.8 , and 7.4, respectively over 3 days. Liang et al. [21] studied the encapsulation of Rifapentin in PLAmicrospheres (RPM). This RPM was dispersed in hydroxyapatite/tricalcium phosphate (HA/TCP) together with adipose tissue mesenchymal stem cells (ASC) and used as a dual-release anti-tuberculosis scaffold for bone engineering. The efficiency of RPM encapsulation and drug loading are around 70.24 and $40.56 \%$, respectively. The drug was released rapidly in the first 4 days, and then the release continued within 62 days. The in vitro release of rifapentine from the composite (ASC + RPM + HA/TCP) was around $88.91 \%$, and the drug release was fast in the first 8 days, and then followed by slow release for more than 76 days.

PLA-based electrospun nanofibers are used in numerous biomedical applications, such as tissue engineering scaffolds, wound healing dressings, drug delivery, dental applications, etc. [22]. Electrospinning technology has excellent advantages such as strong functional adaptability, large surface area, 
easy processing, and good physical properties [23]. Mao et al. [24] studied the release of Rhodamine B $(\mathrm{RhB})$ dye as a drug model from PLA nanofiber membranes. RhB has gradually released from the membranes, and the total cumulative release of $\mathrm{RhB}$ was approximately $47.9 \%$ within 21 days. Sun et al. [25] studied the release of ibuprofen from ibuprofen-loaded PLA (IBU-PLA) micro-fibrous mats. In vitro IBU release from IBU-PLA mats was fast within the first $24 \mathrm{hrs}$, and then the release of the drug was slow within the next 9 days.

This article has developed two dual drug delivery systems dependent on PLA microspheres and PLA electrospun fibers. NOR and TENO are used as drug models. TENO/microspheres are made by evaporation-emulsion method, and then NOR is adsorbed into TENO/microspheres surface through the adsorption process. The NOR-TENO mixture is introduced into PLA, and then an electrospinning process is used to make NOR-TENO/electrospun fibers. The release of drugs at different $\mathrm{pH}$ values was checked, and the antibacterial effects of the two dual systems were evaluated. The in vitro and in vivo cytotoxicity of NOR-TENO/microspheres was studied to evaluate the antitumor activity of two drugs for cancer treatment in the future.

\section{Materials and methods}

\subsection{Chemicals and reagents}

Poly(lactic acid) (PLA) (Grade Ingeo 4032D) was acquired from NatureWorks Co., Minnetonka, USA. The PLA has a density $=1.24 \mathrm{~g} / \mathrm{cc}$ and D-lactide content $=1.4 \mathrm{~mol} \%$, as indicated in the technical datasheet. Polyvinyl alcohol (PVA) $\left(M_{\mathrm{w}}=159.60 \mathrm{~g} / \mathrm{mol}\right)$ was supplied from NICE Chemicals Pvt. Ltd., India, Tenoxicam and Norfloxacin were obtained from Epico, Egypt, Dichloromethane (DCM), Acetone (AC), Dimethylsulfoxide (DMSO), Sodium hydroxide $(\mathrm{NaOH})$, Hydrochloric acid (HCL), Sodium dihydrogen phosphate $\left(\mathrm{NaH}_{2} \mathrm{PO}_{4}\right)$, Disodium hydrogen phosphate $\left(\mathrm{Na}_{2} \mathrm{HPO}_{4}\right)$, Dimethylbenz[ $\left.\alpha\right]$ anthracene (DMBA) were obtained from Sigma-Aldrich Co., USA. The cell lines were obtained from ATCC via Holding company for biological products and vaccines (VACSERA), Cairo, Egypt. The reagents RPMI-1640 medium and MTT were obtained from Sigma Aldrich Co., St. Louis, USA and Fetal Bovine serum was purchased from GIBCO, UK. Bacterial species were obtained from Microbiology Department, Faculty of Science, Tanta University, Egypt.

\subsection{Preparations}

\subsubsection{Preparation of TENO/microspheres}

TENO/PLA microspheres were prepared by the emulsion-evaporation method. Therefore, $0.5 \mathrm{~g}$ of PLA was dispersed in $5 \mathrm{ml}$ dichloromethane (DCM), then $0.025 \mathrm{~g}$ of TENO $(5 \mathrm{w} / \mathrm{w} \%)$ was added and stirred for $24 \mathrm{hrs}$. The aqueous phase containing polyvinyl alcohol (PVA) ( $2 \mathrm{w} / \mathrm{v} \%)$ was prepared by dissolving $2 \mathrm{~g}$ PVA in $100 \mathrm{ml}$ distilled $\mathrm{H}_{2} \mathrm{O}$ at $70^{\circ} \mathrm{C}$ (which acts as an emulsifier and stabilizer for the formulation). Then organic phase was added drop-wise into the aqueous phase under stirring at room temperature and then sonication for $10 \mathrm{~min}$. The resulting suspension was stirred for $24 \mathrm{hrs}$, and the organic solvent was evaporated. The suspension was centrifuged, the supernatant was separated, and the concentration of TENO was determined by UV-vis spectrophotometer at $\lambda_{\max }=373 \mathrm{~nm}$. The precipitate was washed 3 times with distilled $\mathrm{H}_{2} \mathrm{O}$ and dried in an oven at $40^{\circ} \mathrm{C}[26,27]$.

\subsubsection{Adsorption of NOR onto TENO/microspheres \\ [Preparation of NOR-TENO/microspheres]}

A stock solution of NOR (40 ppm) was prepared, and then drug solutions with different concentrations were prepared. The absorbance was determined using a UV-vis spectrophotometer at $\lambda_{\max }=272 \mathrm{~nm}$ and NOR calibration curve was drawn. $0.05 \mathrm{~g}$ of $\mathrm{TENO} /$ microspheres were added into $50 \mathrm{ml}$ of NOR solution (12 ppm), then sonicated for 10 minutes and stirred at $500 \mathrm{rpm}$ for 5 days to complete the surface loading process by direct adsorption. The suspension was centrifuged, then the supernatant was withdrawn by syringe into a quartz cuvette to determine the NOR concentration using UV-vis spectrophotometer at $\lambda_{\max }=272 \mathrm{~nm}$ and the loading [\%] was calculated using Equation (1). Encapsulation and surface loading processes were done in triplet, and the average was calculated:

$$
\begin{aligned}
& \text { Loading }[\%]= \\
& =\frac{\text { amount of NOR in carrier }}{\text { amount of carrier loaded with NOR }} \cdot 100
\end{aligned}
$$

\subsubsection{Preparation of NOR-TENO/electrospun fibers}

PLA $(0.5 \mathrm{~g})$ was added into drugs solution prepared by mixing $0.0125 \mathrm{~g}$ of NOR $(2.5 \mathrm{w} / \mathrm{w} \%)$ and $0.0125 \mathrm{~g}$ of TENO $(2.5 \mathrm{w} / \mathrm{w} \%)$ in $2.5 \mathrm{ml} \mathrm{DCM} / \mathrm{AC}$ 
[volume ratio 1:1], followed by sonication and stirring for $24 \mathrm{hrs}$. The electrospinning process was done using the electrospinning equipment (Electrospinner model, Nanon-01A, MECC Co., LTD, Japan) with a high voltage supply (voltage 0.5 to $30 \mathrm{kV}$ and current $50 \mu \mathrm{A})$ and pump discharge $(0.1$ to $60 \mathrm{ml} / \mathrm{hr})$. A high voltage power source was utilized to produce an electric field of $22.5 \mathrm{kV}$ between a collector and a needle, where the polymer solution was negatively charged so, the collector was positively charged. NOR-TENO/PLA solution was placed in a $10 \mathrm{ml}$ plastic syringe of inner diameter $14.6 \mathrm{~mm}$ with a $16-$ gauge stainless steel needle and a pump system was used to feed a constant solution $(0.6 \mathrm{ml} / \mathrm{hr})$ through the needle. The electrospinning method was performed at relative humidity, the working distance between the collector plate and the needle was $12 \mathrm{~cm}$, and the fibers were placed on the collector plate covered with aluminum foil. The as-spun fibers were put into a desiccator overnight at room temperature for solvent evaporation. The electrospinning conditions such as solution flow rate, fiber receiving distance and receiving device were chosen according to the previous paper [28]. By testing different applied voltages, the fibers were produced at $22.5 \mathrm{kV}$. Different weights of PLA: volumes of DCM+AC were tested till reaching the optimum viscosity, at which the fibers were formed and collected.

\subsubsection{In vitro NOR and TENO release from NOR-TENO/microspheres and NOR-TENO/electrospun fibers}

$0.1 \mathrm{M} \mathrm{NaH}_{2} \mathrm{PO}_{4}$ and $\mathrm{Na}_{2} \mathrm{HPO}_{4}$ were used to prepare the phosphate buffer solution. Then $1 \mathrm{M} \mathrm{HCl}$ and $2 \mathrm{M}$ $\mathrm{NaOH}$ were used to adjust the $\mathrm{pH}$ value of the buffer solutions $(5.4,6.7$, and 7.4). $\mathrm{pH}=5.4$ was selected to mimic the intracellular $\mathrm{pH}$ of the tumor tissues, the slightly acidic $\mathrm{pH}=6.7$ was chosen to mimic the extracellular $\mathrm{pH}$ of tumor tissues, and also the slightly basic $\mathrm{pH}=7.4$ was adapted to mimic the extracellular $\mathrm{pH}$ of normal tissues and the body fluids. $0.01 \mathrm{~g}$ NOR-TENO/microsphere and $0.05 \mathrm{~g}$ NOR-TENO/ electrospun fibers were placed in $10 \mathrm{ml}$ of the buffer solution with $\mathrm{pH}$ values $(5.4,6.7$, and 7.4$)$ as a release medium at $37^{\circ} \mathrm{C}$ under shaking to simulate human body conditions. Then, NOR and TENO drugs amount released from PLA at different times were determined by measuring the concentration of drugs using UV-vis spectrophotometer (NOR at $\lambda_{\max }=272 \mathrm{~nm}$, TENO at $\lambda_{\max }=373 \mathrm{~nm}$ ). The buffer solution was totally replaced by another fresh at every 48 hours, then the release percentage was calculated, and the kinetics was studied.

\subsubsection{In vitro antibacterial test}

The antimicrobial activity of NOR-TENO/microspheres and NOR-TENO/electrospun fibers was determined against gram-positive bacteria such as Bacillus cereus, Staphylococcus aureus, and gramnegative bacteria such as Escherichia coli by utilizing the diffusion method. The diffusion method was used to evaluate the antibacterial activity of the carrier by measuring the inhibition zone. The prepared agar medium was sterilized, poured into a sterile petridish to solidify, then punched with a cork-borer, and the cultured bacterial suspension was inoculated. Drugs carriers' suspension $(100 \mu \mathrm{g} / \mathrm{ml})$ was poured into the holes and incubated for $24 \mathrm{hrs}$ at $37^{\circ} \mathrm{C}$. The inhibition zone was measured, and the antibacterial activity of the carriers was compared with NORTENO as a control [29].

\subsubsection{In vitro antioxidant test}

The ABTS technique was utilized to evaluate the antioxidant properties of NOR-TENO drugs and NORTENO/microspheres. $60 \mathrm{ml}$ (2,20-azino-bis(3-ethylbenzothiazoline-6-sulfonic acid)) (ABTS) was mixed with a solution of manganese (IV) oxide $(3 \mathrm{ml}$, $25 \mathrm{mg} / \mathrm{ml})$ in a solution of phosphate buffer $(0.1 \mathrm{M}$, $\mathrm{pH}=7$ ) then centrifuged and filtered. The absorbance of the green-blue color solution $\left(A_{\text {control }}\right)$ was measured at $\lambda_{\max }=734 \mathrm{~nm}$ and was adjusted at $A=0.5$. The test sample $(20 \mathrm{ml}, 1 \mathrm{mg} / \mathrm{ml})$ is added to phosphate buffer: methanol (1:1). The absorbance of the analyzed sample was measured ( $A_{\text {Tested }}$, and the decrease in color intensity was stated as scavenging activity [\%], according to the Equation (2):

Scavenging activity $[\%]=A_{\text {control }}-\frac{A_{\text {test }}}{A_{\text {control }}} \cdot 100$

Vitamin C (ascorbic acid solution) $(20 \mathrm{ml} 2 \mathrm{mM})$ was used as a control [30].

\subsubsection{In vitro cytotoxicity test}

MTT assay has been used to demonstrate the cytotoxic effects of drugs and drugs carriers on various normal and tumor cell lines. Cell lines including liver-derived hepatocellular carcinoma, HepG2; colorectal cancer originating from the colon, HCT116; 
breast-derived ductal carcinoma of the breast, MCF7; epithelioid adenocarcinoma derived from the cervix, Hela; human lung fibroblast, WI-38 were examined.

\section{Cells culture}

100 units $/ \mathrm{ml}$ penicillin was added to $100 \mu \mathrm{g} / \mathrm{ml}$ streptomycin to prepare the fresh RPMI1640 medium for cell culture. The cells were seeded in $100 \mu 1$ RPMI1640 medium, and $10 \mu 1$ bovine serum was added to each well in a 96-well flat-bottomed culture plate. The cells were incubated in a $5 \% \mathrm{CO}_{2}$ at $37^{\circ} \mathrm{C}$ for $48 \mathrm{hrs}$. After incubation, the cells were treated with different concentrations of NOR-TENO drugs and NOR-TENO/microspheres, then incubated for $24 \mathrm{hrs}$ [31].

\section{MTT assay}

The cell growth was measured by reduction of the yellow dye 3-(4,5-dimethyl-2-thiazolyl) 2,5diphenyl-2H-tetrazolium bromide (MTT) to purple formazan derivatives by using mitochondrial succinate dehydrogenase in living cells. The compound was incubated with cells and $20 \mu$ MTT solution $(5 \mathrm{mg} / \mathrm{ml})$ in a $5 \% \mathrm{CO}_{2}$ atmosphere for $4 \mathrm{hrs}$ at $37^{\circ} \mathrm{C}$. MTT reagent was removed, and $100 \mu \mathrm{DMSO}$ was added to the wells and gently shaken to disperse the purple formazan. The colorimetric evaluation was performed with a plate reader (EXL 800, USA) to calculate the optical density and relative cell viability at $\lambda_{\max }=570 \mathrm{~nm}$ [32], according to the following Equation (3):

Cell viability $[\%]=\frac{A_{570} \text { of treated cells }}{A_{570} \text { of untreated cells }} \cdot 100$

The effect of compounds on tumor and normal cells was represented by $I C_{50}$ values.

\subsubsection{In vivo study on the effect of PLA microspheres loaded NOR-TENO drugs on DMBA induced breast cancer in rats Animals}

Nine adult white female Albino Wistar rats (two months old, $110 \pm 10 \mathrm{~g}$ ) were obtained from the house animal of Tanta University, Egypt. The rats were kept in a laboratory under ideal temperature (18.3$\left.26.7^{\circ} \mathrm{C}\right)$, humidity $(40-70 \%$ ), and light conditions (12 hrs light cycles, where most rats are more active at night), and they obtained a balanced diet of pellets and water. The rats were adapted before the experiment for one month.

\section{Experimental design}

Rats were distributed into 3 equal groups; each group contained 3 rats where, Group I (Control group): normal healthy rats, Group II (DMBA group): rats were injected with $20 \mathrm{mg} / \mathrm{kg}$ of DMBA for one month, and Group III (DMBA+NOR-TENO/microspheres group): rats have received $100 \mathrm{mg} / \mathrm{kg}$ of NOR-TENO/microspheres twice per week for one month after one month from DMBA injection. DMBA injection was subcutaneously by intraperitoneal (IP) and was used as an active chemical inductor of mammary carcinogenesis.

\section{Sampling}

After 8 weeks from the onset of the experiment, the rats were sacrificed under anesthesia. Blood samples have been collected from the portal vein to determine the hematological indicators and biochemical parameters. Mammary gland tissues were collected, washed, and fixed in 10\% phosphate buffer formalin, then stained with hematoxylin and eosin for histological examination [33].

\section{Hematological indicators}

Kits were purchased from Spectrum Diagnostic, Egypt, and Hemoglobin ( $\mathrm{Hb})$ level was measured spectrophotometrically [34]. Glucose [35], Total Cholesterol, and Triglycerides [35] were determined enzymatically. Creatinine was estimated kinetically [36]. Alanine aminotransferase (ALT) and Aspartate aminotransferase (AST) (which are specific enzymes for liver diseases) were determined according to the King method [37], white blood cells (WBCs) were counted using a hemocytometer.

\section{Biochemical parameters}

Lipid peroxidation was determined by measuring Malondialdehyde (MDA) concentration in serum through the release of pink color. Kits were obtained from Biodiganostic, Egypt. Superoxide dismutase (SOD) determination [38] depends on the reduction of nitroblue tetrazolium (NBT) to blue formazan, which is insoluble in water. $1 \mathrm{~mL}$ thiobarbituric acid $(0.67 \%)$ and $0.5 \mathrm{ml}$ of trichloroacetic acid (20\%) was incorporated with $0.5 \mathrm{ml}$ serum. The solution was warmed to $100^{\circ} \mathrm{C}$ for $15 \mathrm{~min}$, and after cooling, $4 \mathrm{ml}$ of $n$-butanol was added, and then the solution 
was centrifuged at $3000 \mathrm{rpm}$ for $15 \mathrm{~min}$. The absorbance of the colored product was determined at $\lambda_{\max }=530 \mathrm{~nm}$ [39]. Nitric oxide (NO) was determined after the conversion of nitrates to nitrites using the Griess reagent method [40]. In short, 30\% zinc (II) sulfate was added to serum to precipitate protein. After centrifugation, $100 \mu \mathrm{l}$ of the supernatant was added to $0.5 \mathrm{~g}$ of granulated cadmium and $0.4 \mathrm{ml}$ of distilled water, followed by stirring overnight and centrifugation. $0.5 \mathrm{ml}$ of the final supernatant was completed with distilled water. After that, Griess reagent containing sulphanilamide and $N$-1-naphthyl ethylene diamine reacted with nitrites and was determined at $\lambda_{\max }=540 \mathrm{~nm}$. The amount of total nitrite (NO) was determined using the nitrite calibration curve.

\section{Preparation of histological samples}

A portion of the mammary gland was fixed in $10 \%$ formalin for $24 \mathrm{hrs}$, dehydrated, cleared, and embedded in paraffin. Tissues were sectioned at $5 \mathrm{~mm}$ thickness, dewaxed, rehydrated, and processed for hematoxylin and eosin staining. The slides were observed under light microscopy to analyze ductal carcinoma.

\section{Statistical analysis}

A one-way analysis of variance (ANOVA) (Graph Pad InStat version 3.06, San Diego, CA, USA) was applied for statistical analysis of obtained data followed by the Duncan multiple tests to compare the mean, standard deviation (SD) values of different groups. All analyses were performed using Co Stat 6.311. Values of $P \leq 0.05$ were considered significant.

\section{Ethical protocol}

International ethical considerations for the study using laboratory animals were respected during the experimental process [IACUC-SCI-TU-0225].

\subsubsection{Characterization techniques}

Fourier transform infrared spectroscopy (FTIR) (JASCO FT/IR-4100 model, Japan) at $4 \mathrm{~cm}^{-1}$ resolution and 64 scans per sample. The samples were pelletized with a $\mathrm{KBr}$ disk and determined within the wavenumber range $4000-400 \mathrm{~cm}^{-1}$. X-ray powder diffraction (XRD) patterns were evaluated at room temperature using (GNR, APD 2000 PRP step scan $\mathrm{X}$-ray Diffractometer), with $\mathrm{Cu}$ as anode material and graphite monochromator operated at a voltage of $40 \mathrm{kV}$ in the range of 4-80 (20) with a pass time
$0.05 \mathrm{sec}$. The crystallite size of NOR-TENO/microspheres and NOR-TENO/electrospun fibers was calculated by Debye-Scherer's equation (Equation (4), and it was around 14 and $21 \mathrm{~nm}$, respectively:

$$
D=\frac{k \cdot \lambda}{\beta \cdot \cos \theta}
$$

where $D$ is the crystallite size, $k$ is a constant (0.94), $\lambda$ is the wavelength of the X-ray radiation $(0.15406 \mathrm{~nm}), \beta$ is the line width at half maximum height, and $\theta$ is the diffraction angle.

Scanning electron microscopy (SEM) was used to study sample morphology, where the samples were put on double-sided carbon tape and uniformly coated with gold by using an ion-sputter for $10 \mathrm{~min}$ and examined under SEM (A JEOL SEM, JSM-6510LV) supplied by EDX operated at $30 \mathrm{kV}$ at different magnifications. SEM images (Figure 3a), 10 fibers from each image (total $=100$ fibers) were measured to calculate the average size of fibers, and (Figure 5a), 15 spheres from each image (total $=110$ spheres) were used to calculate the average size of spheres. UV-vis absorption spectra for all sample solutions placed in quartz cuvette were evaluated using UV-vis spectroscopy (UV-2101 PC). The pH of buffer solutions was measured using a 3510 bench Jenway $\mathrm{pH}$ meter. High dispersion of samples was made using Ultrasonication (Ultrasonic Cleaner, KSU-100 model, $220 \mathrm{~V}$; $60 \mathrm{~W}$ power, made in Korea by Human Lab Inc.).

\section{Results and discussion}

In this article, TENO/microspheres were prepared by emulsion-evaporation method followed by loading NOR drug through adsorption process to form NORTENO/microspheres. In addition, NOR-TENO/electrospun fibers were prepared by the electrospinning process. Drugs released from microspheres and electrospun fibers systems were studied. In vitro antibacterial, antioxidants, cytotoxicity assays against different tumor cells were investigated. Moreover, in vivo induced breast cancer in rats was studied, and the influence of microspheres-loaded drugs on hematological, biochemical, and histopathological data was examined.

\subsection{Characterization of NOR- TENO/microspheres and NOR-TENO/electrospun fibers}

FTIR is a very effective technique to determine the interaction between functional groups in NOR, 
TENO, PLA in NOR-TENO/microspheres and NORTENO/electrospun fibers. As shown in Figure 1, TENO drug shows characteristic peaks located at 1643 and $1595 \mathrm{~cm}^{-1}(-\mathrm{C}=\mathrm{O}, \mathrm{C}=\mathrm{N}), 1488 \mathrm{~cm}^{-1}(-\mathrm{C}-\mathrm{H}$ deformations), $1422 \mathrm{~cm}^{-1}$ (heterocyclic ring), 1388 and $1328 \mathrm{~cm}^{-1}$ (methyl group deformation), $1245 \mathrm{~cm}^{-1}$ (O-H bending), 1198 and $1149 \mathrm{~cm}^{-1}$ (-C-O stretching). FTIR spectrum of NOR shows characteristic peaks located at 1625 and $1735 \mathrm{~cm}^{-1}$ (carbonyl stretching of pyridine-keto and carboxylic group), $1468 \mathrm{~cm}^{-1}$ (N-H of quinolones), 1393, 1340 and $1268 \mathrm{~cm}^{-1}$ (-O-H bending), 1092 and $1031 \mathrm{~cm}^{-1}$ (C-F bending), $931 \mathrm{~cm}^{-1}$ (N-H bending). PLA shows characteristic peaks at $3449 \mathrm{~cm}^{-1}$ (hydroxyl stretching), $2999 \mathrm{~cm}^{-1}$ (-CH- stretching), $2947 \mathrm{~cm}^{-1}\left(-\mathrm{CH}_{2}\right.$ stretching), $2884 \mathrm{~cm}^{-1}$ (- $\mathrm{CH}_{3}$ stretching), $1768 \mathrm{~cm}^{-1}$ (carbonyl stretching of ester), 1385 and $1456 \mathrm{~cm}^{-1}$ (symmetric and asymmetric deformation of $-\mathrm{CH}_{3}$ ) and peak at $1187 \mathrm{~cm}^{-1}(-\mathrm{C}-\mathrm{O}-\mathrm{C}-$ stretching $)$ [41]. The PLA hydroxyl stretching peak at $3449 \mathrm{~cm}^{-1}$ was slightly shifted to a lower wavelength in NOR-TENO/ microspheres and was split into 3 small peaks and shifted to a higher wavelength in NOR-TENO/electrospun fibers. The characteristic peak of PLA at $1768 \mathrm{~cm}^{-1}$ ( $-\mathrm{C}=\mathrm{O}$ stretching) was slightly shifted to 1763 and $1756 \mathrm{~cm}^{-1}$ in NOR-TENO/microspheres and NOR-TENO/electrospun fibers, respectively. The shifts in NOR-TENO/microspheres and NORTENO/electrospun fibers were due to the electrostatic interaction (physical interaction) between NOR, TENO, and PLA matrix during the encapsulation process [42]. Direct adsorption of NOR onto the TENO/microspheres surface also occurred through the electrostatic interactions.

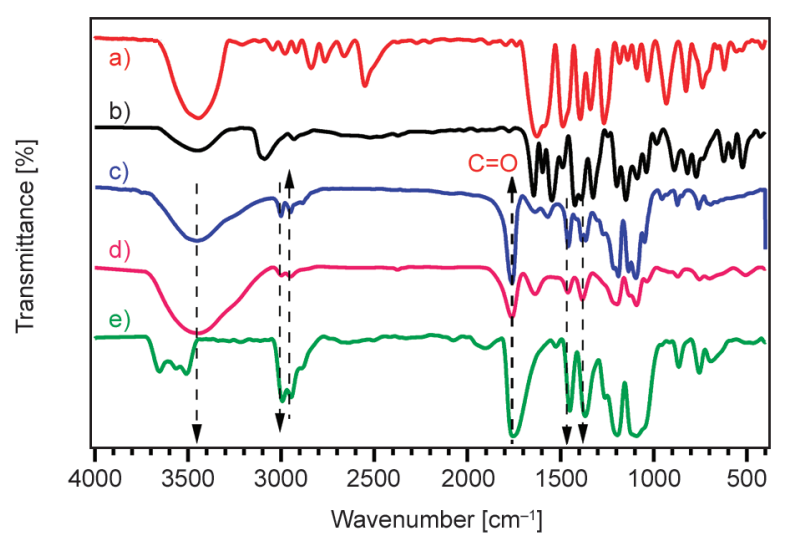

Figure 1. FTIR spectra of a) NOR drug, b) TENO drug, c) PLA, d) NOR-TENO/microspheres, and e) NORTENO/electrospun fibers.
XRD patterns of NOR, TENO, PLA, NOR-TENO/ microspheres, and NOR-TENO/electrospun fibers are shown in Figure 2. XRD (Figure 2a) of NOR shows several peaks located at $2 \theta=10.3,11.05,13$, $19,20.45,21.3,24.8,32.2,34.4,38.25,41.9^{\circ}$ [41], and for TENO, there are many peaks located at $2 \theta=$ $11.55,12.05,12.45,14.45,16,16.8,18.5,19.25,21$, $21.85,23.35,25.4,25.8,26.25,28.35,29.35,34.4$, $38.3^{\circ}$ [43]. XRD of NOR and TENO showed sharp and intense crystallinity peaks, indicating a highly crystalline nature.

XRD pattern (Figure 2b) of PLA shows characteristic peaks located at $2 \theta=17.05,19.30$, and $22.85^{\circ}$ [44], indicating the presence of crystalline phases. The XRD pattern of NOR-TENO/microspheres shows that peaks of PLA were slightly shifted by loading drugs to $2 \theta=16.7,18.30$, and $19.25^{\circ}$, the drug peaks did not appear in the XRD due to the low amount of drugs in respect to PLA [45]; thus the slight shift in the peaks may be related either to instrumental causes or internal effects of the sample. XRD pattern (Figure 2c) of NOR-TENO/electrospun fibers displayed a broad peak which split into two peaks, located at $2 \theta=11.35$ and $13.20^{\circ}$, indicating a lower degree of crystallinity or changes into an amorphous phase of the drug, and confirming the nanostructure of the sample [46].

SEM images of NOR-TENO/electrospun fibers are shown in Figure 3. SEM images show uniform and smooth fibers. The average diameter of fibers was calculated (Figure 3) to be $550 \pm 270 \mathrm{~nm}$ (Figure 4). For NOR-TENO/electrospun fibers (encapsulation was confirmed by SEM), SEM images (Figure 3e and $3 f$ ) indicated that there are no drug molecules on the surface of the fiber, and these images show the encapsulated drug molecules.

SEM micrographs of microspheres are shown in Figure 5. SEM images show spherical porous morphology. The average diameter of spheres was calculated from (Figure 4) to be $9 \pm 7 \mu \mathrm{m}$. No visible drug crystals were found in the SEM images. Many big particles could easily be seen near the microspheres; these particles are largely remnants of PVA that are used as emulsifiers and stabilizers for the PLA formulation.

NOR-TENO/microspheres encapsulation was confirmed by UV as shown in Figure 6a, which indicates the adsorption of NOR by TENO/microspheres during 5 days. As shown in Figure 6a, no peaks for 

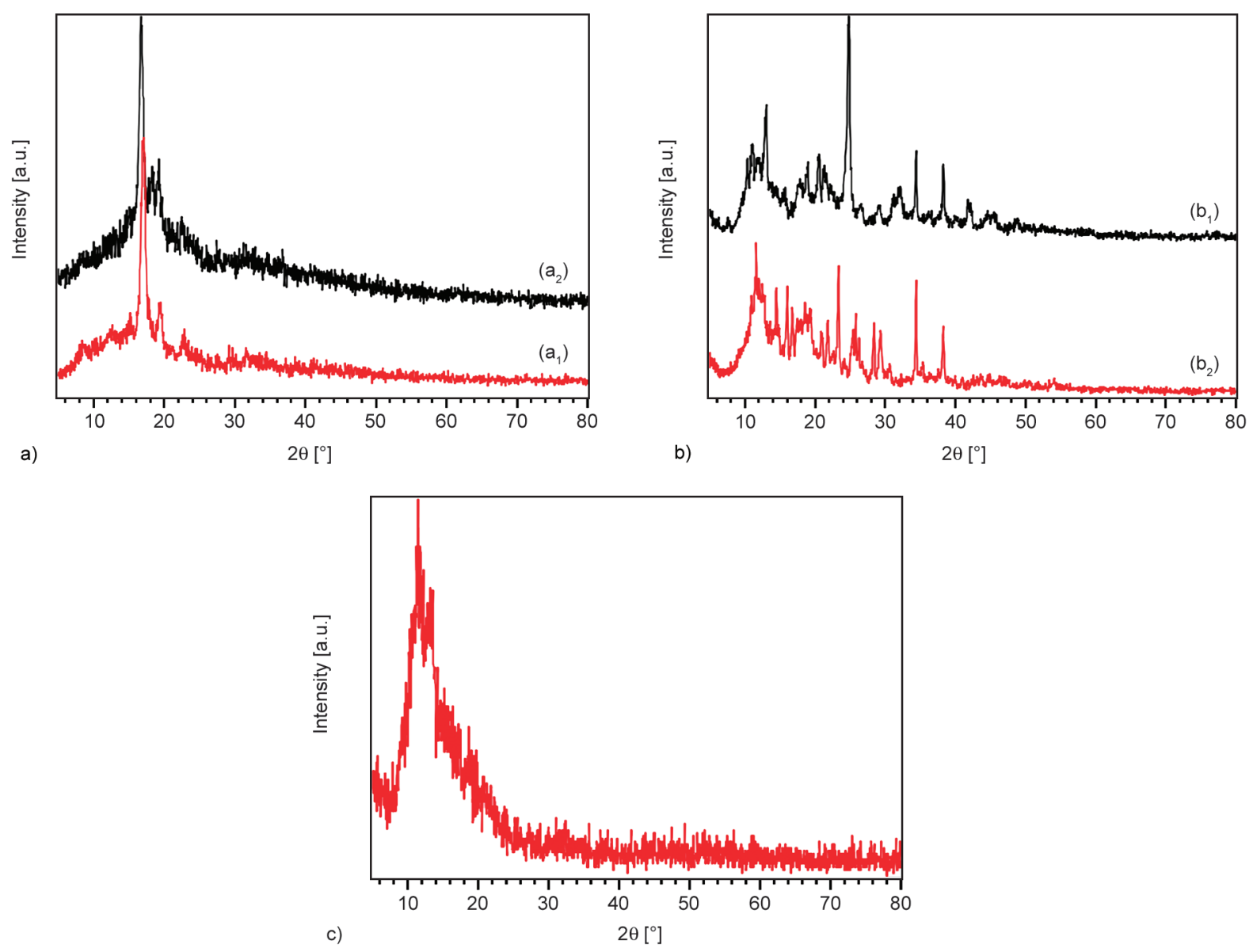

Figure 2. XRD patterns of (a): $a_{1}$ ) NOR, $a_{2}$ ) TENO, (b): $b_{1}$ ) PLA, $b_{2}$ ) NOR-TENO/microspheres and (c): NOR-TENO/electrospun fibers.

TENO appeared, confirming the preservation of the drug inside the spheres, and there is no TENO on the surface of the spheres. Figure $6 \mathrm{~b}$ of NOR-TENO release of the same sample under release conditions (buffer solution with different $\mathrm{pHs}$ and temperature $37^{\circ} \mathrm{C}$ ), as noticeable, there are peaks for the adsorbed NOR and the encapsulated TENO, indicating the presence of encapsulated TENO inside the spheres and referring to the preservation of the encapsulated TENO during the adsorption process.

\subsection{Drugs loading study of}

\section{NOR-TENO/microspheres and}

NOR-TENO/electrospun fibers

The TENO encapsulation [\%] was calculated to be $(59.35 \pm 5.05 \%)$ in $\mathrm{TENO} /$ microspheres upon using ( $25 \mathrm{mg}$ of TENO: $0.5 \mathrm{~g}$ of PLA). Then NOR was loaded onto TENO/microspheres by direct adsorption of NOR to the surface of microspheres depending on non-covalent chemical interactions such as electrostatic and van Der Waals interactions between drug and PLA, and the NOR loading [\%] was calculated to be $(50.08 \pm 6.38 \%)$, upon using $(0.12 \mathrm{mg}$ of NOR: $0.5 \mathrm{~g}$ of $\mathrm{TENO} / \mathrm{microspheres)}$ to form NORTENO/microspheres.

A mixture of drugs was blended with PLA $(100 \%$ TENO and $100 \%$ NOR) (12.5 mg of NOR $+12.5 \mathrm{mg}$ of TENO: $0.5 \mathrm{~g}$ of PLA), then via electrospinning process, NOR-TENO/electrospun fibers were produced.

\subsection{In vitro drugs release study of NOR-TENO/microspheres and NOR-TENO/electrospun fibers}

The in vitro release performance of NOR and TENO drugs from microspheres and electrospun fibers at various $\mathrm{pH}$ are displayed in (Figure 7). Release of TENO from microspheres showed a slow profile and reached $22.58,15.33,12.25 \%$ at $\mathrm{pH}(7.4,6.7,5.4)$, respectively, after 20 days. However, the release of adsorbed NOR was fast and reached 98.82, 91.24, $92.92 \%$ in $\mathrm{pH}(7.4,6.7,5.4)$, respectively after 20 days. The slow-release of TENO was explained by the entrapment of TENO molecules in the center of 
PLA microspheres, and lipophilic drugs can distribute more homogeneously in the PLA matrix; hence,
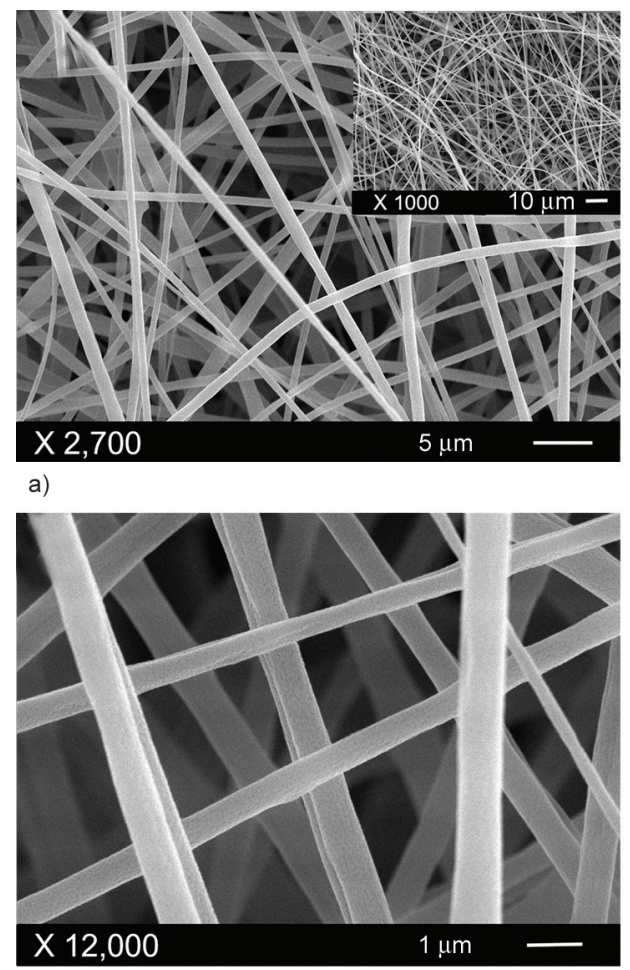

c)

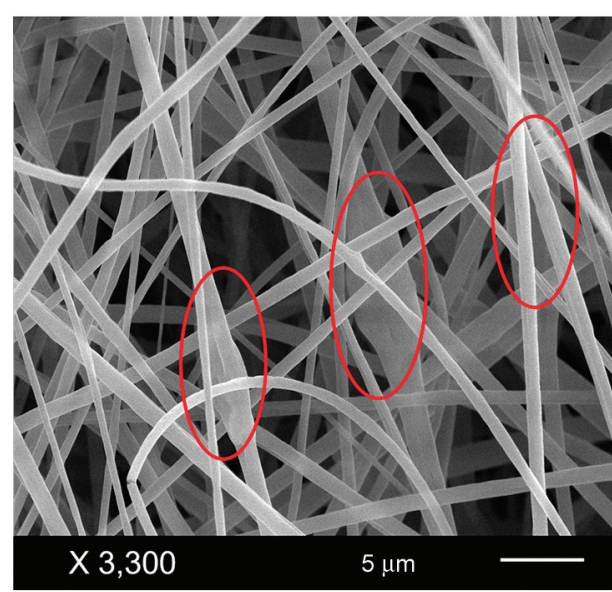

e) the drug was released over a long time. Fast release of NOR may be related to a weak bond between the

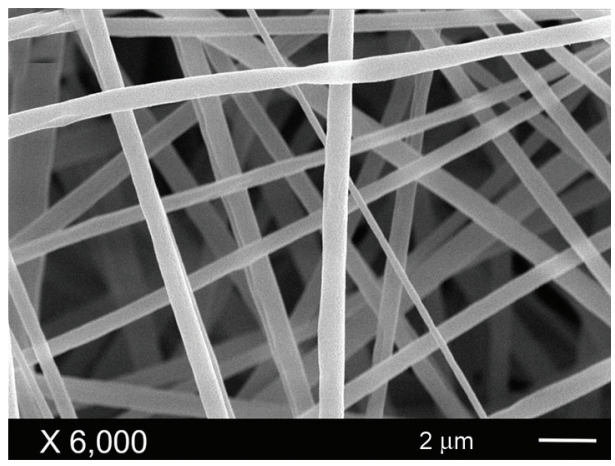

b)

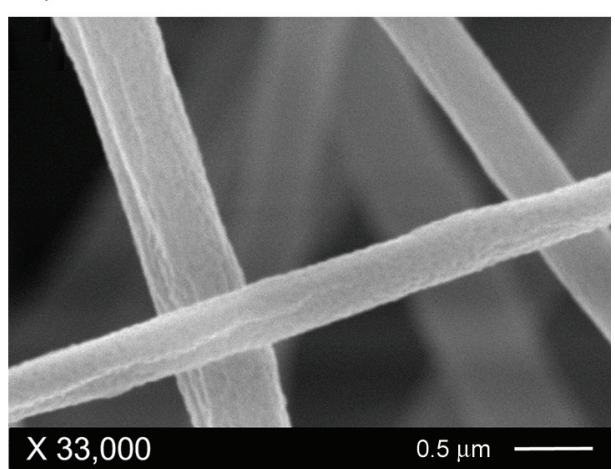

d)

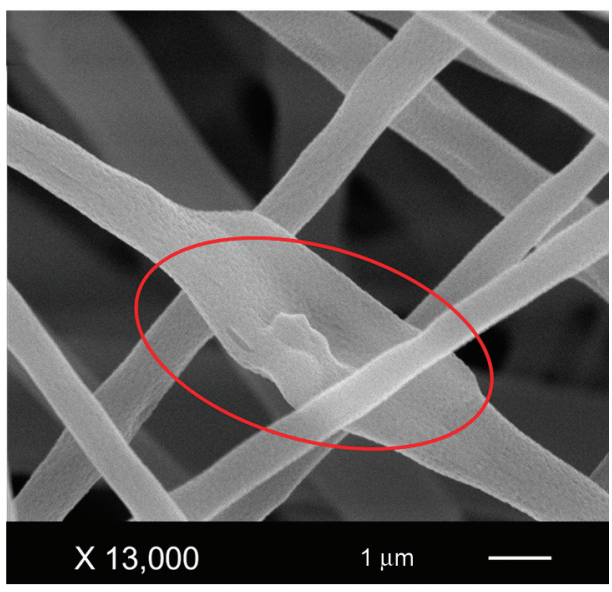

f)

Figure 3. SEM micrographs of NOR-TENO/electrospun fibers at different magnifications (a-f) at $15 \mathrm{kV}$.
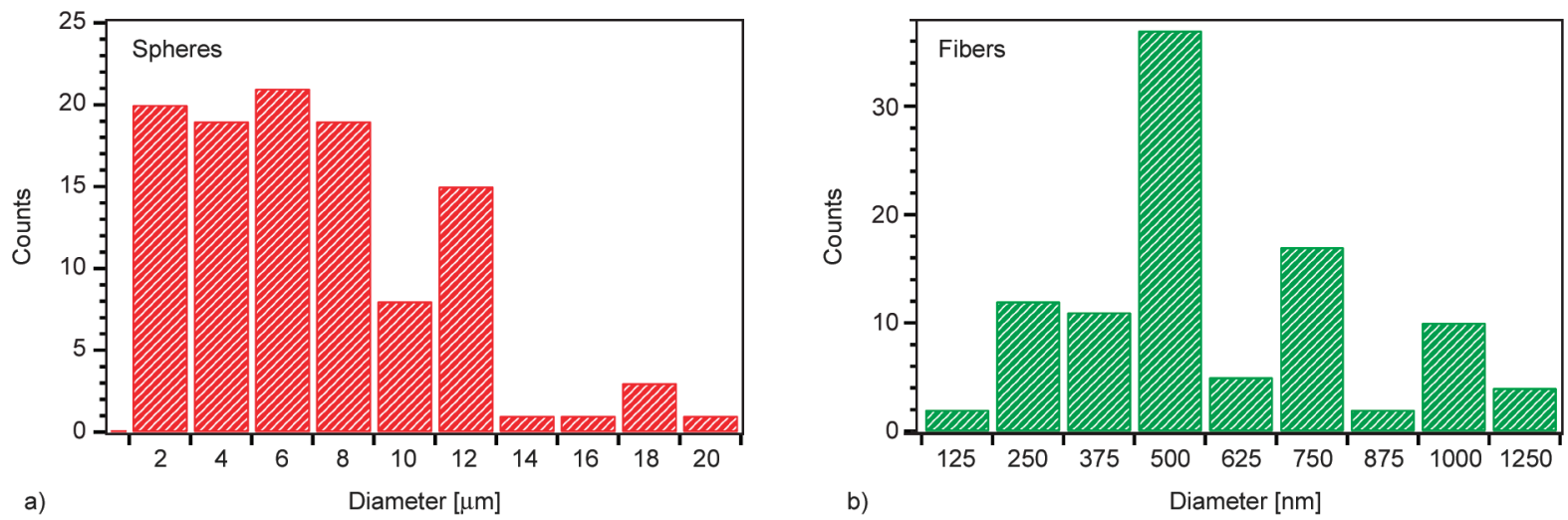

Figure 4. Histogram of the spheres (a) and fibers (b). 


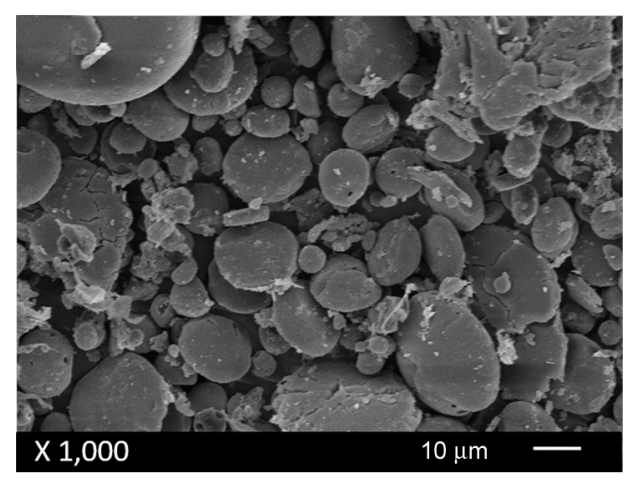

a)

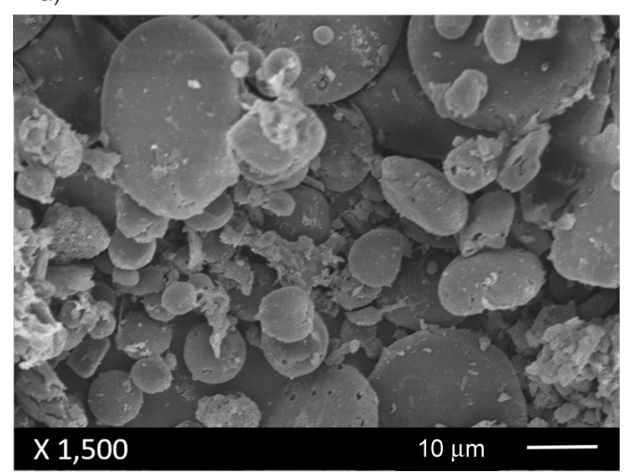

c)

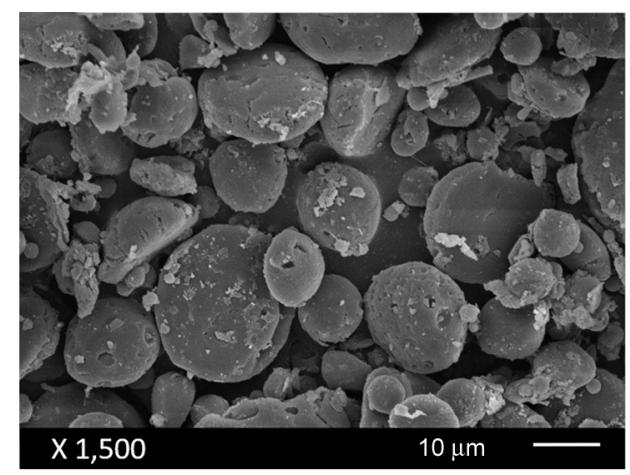

b)

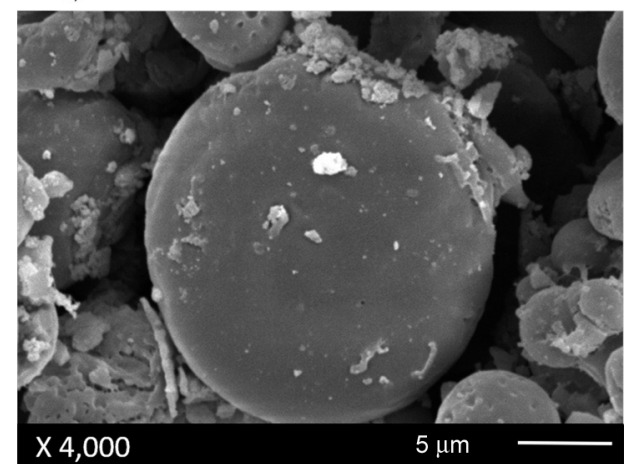

d)

Figure 5. SEM micrographs NOR-TENO/microspheres at different magnifications (a-d) at $10 \mathrm{kV}$.

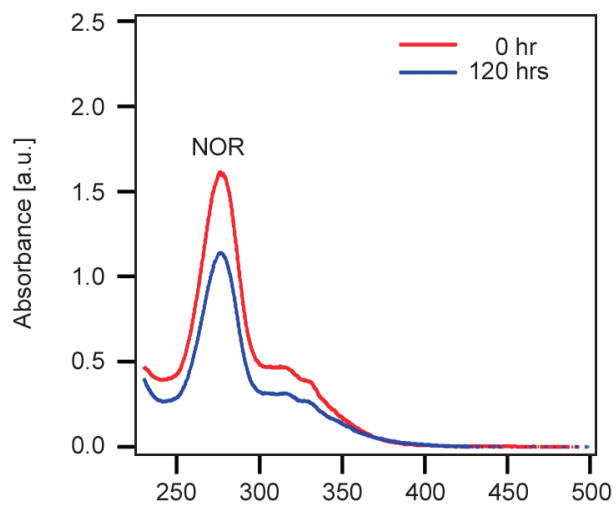

a)

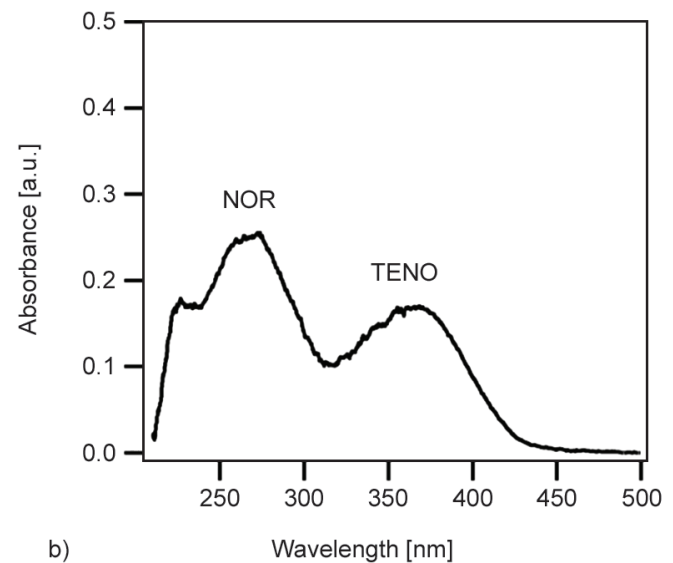

Figure 6. Absorbance curve of NOR-TENO/microspheres: a) NOR loading by TENO/microspheres during 5 days and b) NOR-TENO release of the same sample under release conditions (buffer solution with different pHs and temperature $37^{\circ} \mathrm{C}$ ).

drug and the microsphere surface at different $\mathrm{pH}$ media. Cohen et al. [47] reported that protein was released within 76 days using PLGA microspheres by diffusion via a tortuous water-filled path in the material and bioerosion via degradation of PLGA microspheres by hydrolysis of ester groups. Morirera et al. [48] reported that the in vitro release of 5-FU from PLA microspheres with various molecular weights was $70-85 \%$ over 7 days. Polymeric microsphere particles with a size $\sim 6 \mu \mathrm{m}$ controlled the diffusion rate of the drug where it slows down drug release due to the lower surface area of these large particles [49]. Lizambard et al. [50] found that PLGA-based implants were formed in situ to control the release of an anti-inflammatory drug (ibuprofen) and antiseptic drug (chlorhexidine) within a few weeks, and the release of ibuprofen was slower than chlorhexidine. Sun et al. [51] loaded ciprofloxacin and ginsenoside into PLGA microspheres dispersed thermo-sensitive hydrogel. In vitro drug release exhibited a faster and short release manner of ginsenoside in hydrogel (within $48 \mathrm{hrs}$ ), while ciprofloxacin showed a sustained and long-term release performance (for 12 days). 

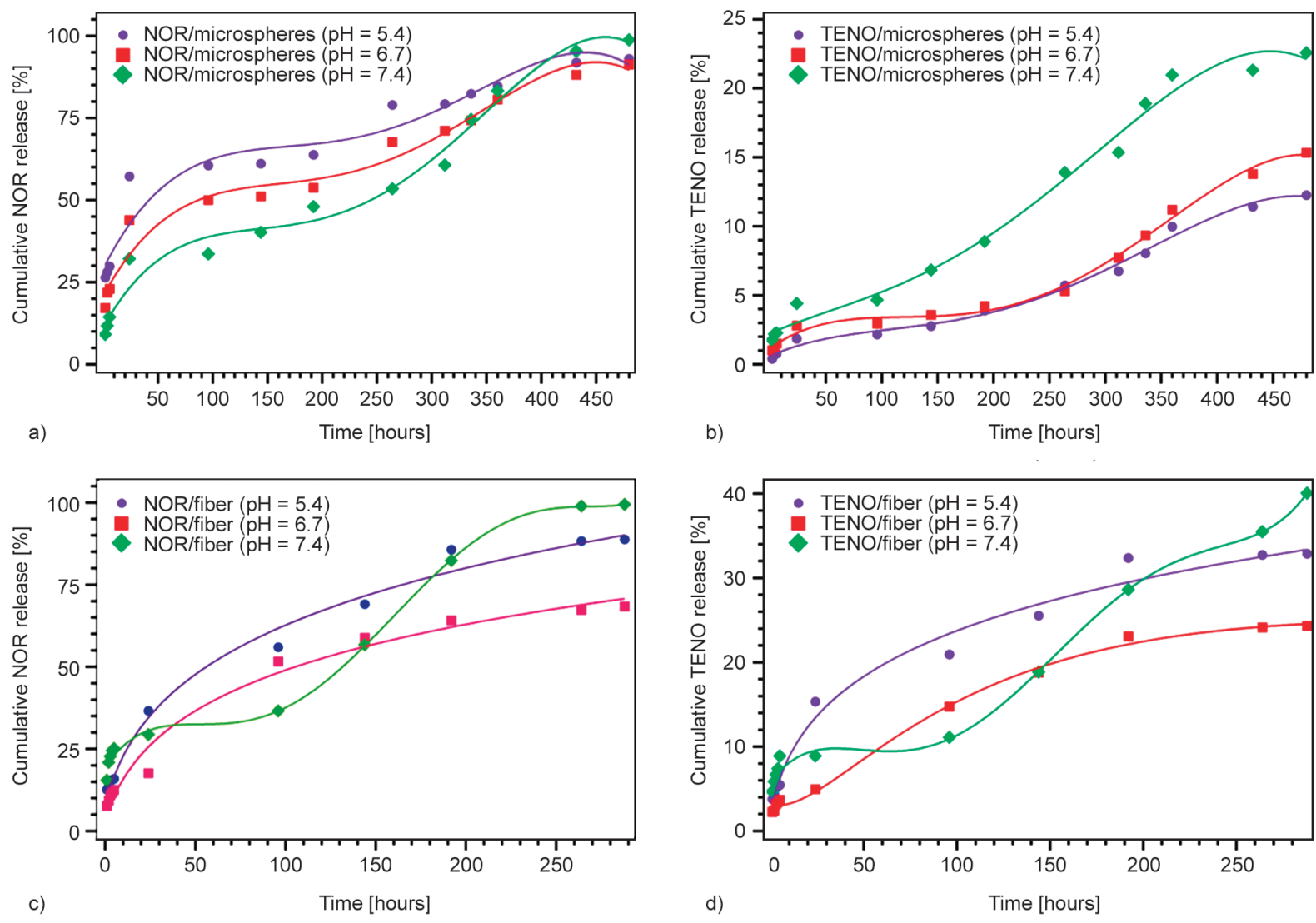

Figure 7. In vitro NOR and TENO release behaviors from (a, b) NOR-TENO/microspheres and (c, d) NOR-TENO/electrospun fibers at different $\mathrm{pH}$ media $(5.4,6.7,7.4)$.

The release of NOR from NOR-TENO/electrospun fibers was fast, and almost $88,68,100 \%$ of NOR were released within 12 days at $\mathrm{pH}(5.4,6.7,7.4)$, respectively. In vitro NOR release studies from electrospun fibers demonstrated two stages of release: rapid release of the drugs and then slower second stage until reaching persistence. Approximately 85, 64, $82 \%$ of the entrapped NOR were released at $\mathrm{pH}(5.4$, $6.7,7.4)$, respectively, during the first eight days of the release process, then the release was gradually increased for the next four days. The release behavior of TENO from NOR-TENO/electrospun fibers was slow and was almost $32,24,40 \%$ within 12 days at $\mathrm{pH}(5.4,6.7,7.4)$, respectively. The rapid release may be due to the existence of drug molecules close to the surface of polymer fibers. Compared with PLA microspheres, the extremely substantial surface area of electrospun PLA fibers leads to a more rapid fibers release. Zhu et al. [28] reported that $50 \%$ of lovastatin drugs are released from PLA electrospun fibers over the first day (burst release). A slower release that approaches a plateau after 7 days and PLA electrospun fiber has a higher release rate compared to PLA films.
The kinetic release models as Pseudo-first order, Higuchi, Hixon-Crowell models, and KorsmeyerPeppas were applied to release curves of NORTENO from microspheres and electrospun fibers at $\mathrm{pH}(7.4,6.7$, and 5.4) (Table 1). It was found that the release of NOR-TENO from microspheres and electrospun fibers followed Higuchi and Hixon-Crowell kinetic models at $\mathrm{pH}$ (7.4). Korsmeyer-Peppas mathematical model was applied for NOR-TENO/microspheres and NOR-TENO/electrospun fiber (Table 1) to understand the release mechanism, as Korsmeyer-Peppas was fitted for the first $60 \%$ drugs release. The $n$ value indicates that NOR releases behavior from NOR-TENO/microspheres exhibited a Fickian release (case I transport), and NOR release from NOR-TENO/electrospun fibers exhibited a non-Fickian release. In addition, lower $k$ values indicate slower release behaviors.

\subsection{In vitro antibacterial activity}

When testing the antibacterial action of NOR-TENO/ microspheres (Figure 8) against $S$. aureus and B. cereus, it was observed that NOR-TENO/microspheres had good activity against $B$. cereus and $S$. aureus 
Table 1. Release kinetics models of NOR and TENO release profiles from NOR-TENO/microspheres and NOR-TENO/electrospun fibers at $\mathrm{pH}(7.4,6.7,5.4)$.

\begin{tabular}{|c|c|c|c|c|c|}
\hline $\begin{array}{l}\text { Release kinetics } \\
\text { models }\end{array}$ & pH media & $\begin{array}{l}\text { NOR from } \\
\text { TENO-NOR/ } \\
\text { microspheres }\end{array}$ & $\begin{array}{l}\text { TENO from } \\
\text { TENO-NOR/ } \\
\text { microspheres }\end{array}$ & $\begin{array}{c}\text { NOR from } \\
\text { NOR-TENO/ } \\
\text { electrospun fibers }\end{array}$ & $\begin{array}{c}\text { TENO from } \\
\text { NOR-TENO/ } \\
\text { electrospun fibers }\end{array}$ \\
\hline \multirow{6}{*}{$\begin{array}{l}\text { First order } \\
{\left[\mathrm{hr}^{-1}\right]}\end{array}$} & \multirow{2}{*}{5.4} & $R^{2}=0.916$ & $R^{2}=0.765$ & $R^{2}=0.947$ & $R^{2}=0.913$ \\
\hline & & $K_{1}=0.043$ & $K_{1}=0.0014$ & $K_{1}=0.074$ & $K_{1}=0.009$ \\
\hline & \multirow{2}{*}{6.7} & $R^{2}=0.899$ & $R^{2}=0.919$ & $R^{2}=0.935$ & $R^{2}=0.897$ \\
\hline & & $K_{1}=0.042$ & $K_{1}=0.0009$ & $K_{1}=0.034$ & $K_{1}=0.008$ \\
\hline & \multirow{2}{*}{7.4} & $R^{2}=0.641$ & $R^{2}=0.975$ & $R^{2}=0.924$ & $R^{2}=0.954$ \\
\hline & & $K_{1}=0.064$ & $K_{1}=0.0011$ & $K_{1}=0.205$ & $K_{1}=0.017$ \\
\hline \multirow{6}{*}{$\begin{array}{l}\text { Higuchi } \\
{\left[\mathrm{hr}^{-1 / 2}\right]}\end{array}$} & \multirow{2}{*}{5.4} & $R^{2}=0.957$ & $R^{2}=0.774$ & $R^{2}=0.919$ & $R^{2}=0.911$ \\
\hline & & $K_{\mathrm{H}}=4.270$ & $K_{\mathrm{H}}=0.651$ & $K_{\mathrm{H}}=9.680$ & $K_{\mathrm{H}}=3.347$ \\
\hline & \multirow{2}{*}{6.7} & $R^{2}=0.973$ & $R^{2}=0.92$ & $R^{2}=0.7831$ & $R^{2}=0.881$ \\
\hline & & $K_{\mathrm{H}}=5.376$ & $K_{\mathrm{H}}=0.417$ & $K_{\mathrm{H}}=8.092$ & $K_{\mathrm{H}}=3.371$ \\
\hline & \multirow{2}{*}{7.4} & $R^{2}=0.940$ & $R^{2}=0.977$ & $R^{2}=0.956$ & $R^{2}=0.961$ \\
\hline & & $K_{\mathrm{H}}=6.624$ & $K_{\mathrm{H}}=0.510$ & $K_{\mathrm{H}}=14.372$ & $K_{\mathrm{H}}=6.028$ \\
\hline \multirow{6}{*}{$\begin{array}{l}\text { Hixon-Crowell } \\
{\left[\mathrm{hr}^{-1}\right]}\end{array}$} & \multirow{2}{*}{5.4} & $R^{2}=0.957$ & $R^{2}=0.774$ & $R^{2}=0.919$ & $R^{2}=0.911$ \\
\hline & & $K_{\mathrm{HC}}=0.711$ & $K_{\mathrm{HC}}=0.108$ & $K_{\mathrm{HC}}=1.613$ & $K_{\mathrm{HC}}=0.557$ \\
\hline & \multirow{2}{*}{6.7} & $R^{2}=0.973$ & $R^{2}=0.921$ & $R^{2}=0.783$ & $R^{2}=0.881$ \\
\hline & & $K_{\mathrm{HC}}=0.896$ & $K_{\mathrm{HC}}=0.069$ & $K_{\mathrm{HC}}=1.348$ & $K_{\mathrm{HC}}=0.561$ \\
\hline & \multirow{2}{*}{7.4} & $R^{2}=0.940$ & $R^{2}=0.977$ & $R^{2}=0.956$ & $R^{2}=0.961$ \\
\hline & & $K_{\mathrm{HC}}=1.104$ & $K_{\mathrm{HC}}=0.085$ & $K_{\mathrm{HC}}=2.395$ & $K_{\mathrm{HC}}=1.004$ \\
\hline \multirow{9}{*}{$\begin{array}{l}\text { Korsmeyer-Peppas } \\
{\left[\mathrm{hr}^{\mathrm{n}}\right]}\end{array}$} & \multirow{3}{*}{5.4} & $R^{2}=0.768$ & $R^{2}=0.702$ & $R^{2}=0.975$ & $R^{2}=0.947$ \\
\hline & & $n=0.177$ & $n=$ not fitted & $n=0.375$ & $n=$ not fitted \\
\hline & & $K=-0.263$ & $K=-1.067$ & $K=-0.394$ & $K=-0.348$ \\
\hline & \multirow{3}{*}{6.7} & $R^{2}=0.806$ & $R^{2}=0.696$ & $R^{2}=0.934$ & $R^{2}=0.973$ \\
\hline & & $n=0.255$ & $n=$ not fitted & $n=0.548$ & $n=$ not fitted \\
\hline & & $K=-0.383$ & $K=-0.817$ & $K=-0.537$ & $K=-0.655$ \\
\hline & \multirow{3}{*}{7.4} & $R^{2}=0.868$ & $R^{2}=0.975$ & $R^{2}=0.859$ & $R^{2}=0.845$ \\
\hline & & $n=0.369$ & $n=$ not fitted & $n=0.525$ & $n=$ not fitted \\
\hline & & $K=-0.566$ & $K=-0.975$ & $K=-0.600$ & $K=-0.745$ \\
\hline
\end{tabular}

compared to drugs. The antibacterial ability of NORTENO/microspheres against $E$. coli is more effective

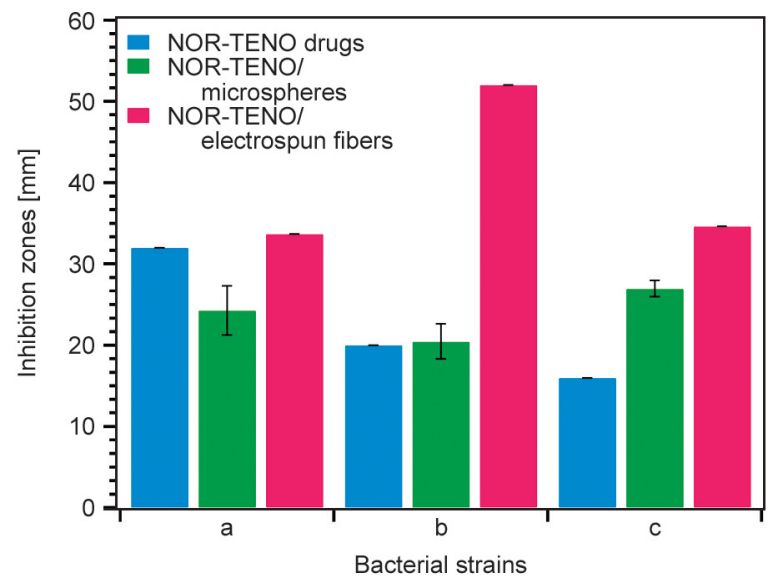

Figure 8. Antibacterial activity of NOR-TENO drugs, NORTENO/microspheres, and NOR-TENO/electrospun fibers against different bacterial strains, where, a) B. cereus, b) S. aureus and c) E. coli. than standard NOR-TENO drugs in killing bacteria The antibacterial effect of NOR-TENO/electrospun fiber (Figure 8) on S. aureus was increased by about 2.5 times, it has a strong antibacterial effect on $B$. cereus, and its antibacterial effect on $E$. coli is about 2 times higher than that of the free mixed drugs. The inhibition zone of $S$. aureus, E. coli and B. cereus were $20.45 \pm 2.15,26.97 \pm 1.02$, and $24.27 \pm 3.02 \mathrm{~mm}$, respectively by the action of NOR-TENO/microspheres and was $52 \pm 0,34.66 \pm 0$, and $33.66 \pm 0 \mathrm{~mm}$, respectively by the action of NOR-TENO/electrospun fibers. By comparing NOR-TENO/microspheres with NOR-TENO/electrospun fibers in eradicating different bacterial strains, it was found that NOR-TENO/ electrospun fibers give better results. Sun et al. [51] revealed that the loading of ciprofloxacin and ginsenoside into PLGA showed a high level of synergism versus methicillin-resistant Staphylococcus and aureus methicillin-sensitive Staphylococcus aureus. 
Budai-Szücs et al. [52] studied the antimicrobial effect of electrospun PLA fiber devices containing metronidazole disks against five bacterial strains. Some strains are not sensitive to metronidazole (P. micra, E. corrodens and A. actinomycetes); however drug is extraordinarily effective against other strains (P. intermedia, F. nucleatum). The longest inhibition time (13 days) of metronidazole-sensitive bacteria may be due to the sustained release of metronidazole present inside the fibers and the slower penetration of aqueous media into them.

\subsection{In vitro antioxidant capacity}

The ability of NOR-TENO drugs and NOR-TENO/ microspheres to scavenge the free radical cation (2,20-azino-bis(3-ethyl-benzothiazoline-6-sulfonic acid)) (ABTS) was assessed. The results are shown in (Figure 9), NOR-TENO drug has the moderate ability (35.5\%) to scavenge free radical cations compared to ascorbic acid (88.6\%), which has high antioxidant activity. Also, NOR-TENO/microspheres showed moderate antioxidant properties (32.1\%) compared to ascorbic acid (88.6\%), which has a high capability of scavenging free radical cations. Results demonstrated that NOR-TENO/microspheres presented inferior activity than free NOR-TENO, and this may be related to the sustained release of NORTENO through PLA microspheres. It was found that the antioxidant capacity of vanillin-loaded PLA nanoparticles to scavenge 2,2-azino-bis(3-ethylbenzothiazoline-6-sulfonic acid) radical (ABTS) was getting close to free vanillin and, due to its sustained release [53].

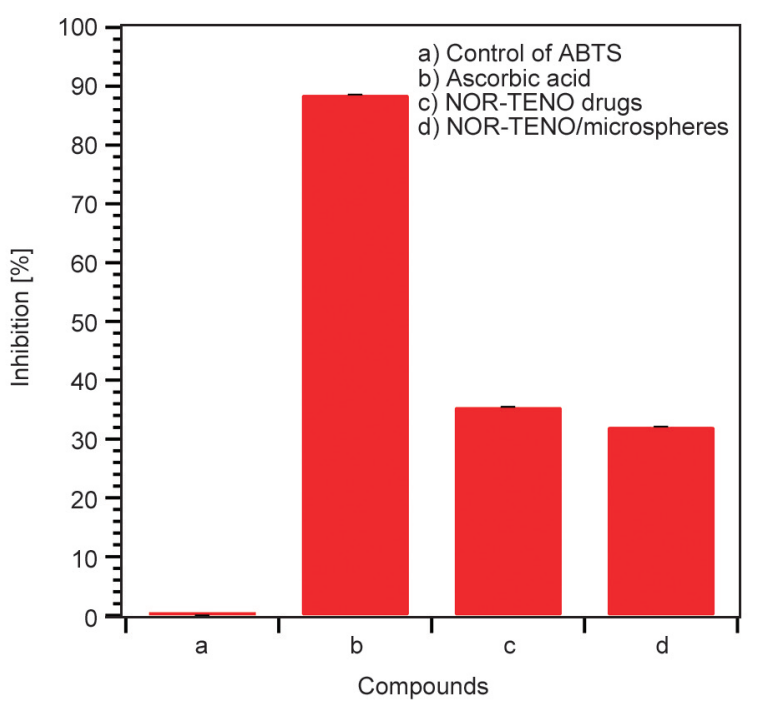

Figure 9. Antioxidant activity of compounds compared to ascorbic acid as a positive control.
The antioxidant activity of Tragacanth gum-cl-poly (lactic acid-co-itaconic acid) hydrogel $(640 \mathrm{~g} / \mathrm{ml})$ recorded $43.85 \%$ scavenging of free radicals, and by increasing hydrogel concentration, the antioxidant activity [\%] increased [54].

\subsection{In vitro antitumor evaluation}

The cytotoxicity of free NOR-TENO and NORTENO/microspheres was tested calorimetrically on various human tumor and normal cell lines such as human hepatocellular carcinoma (HepG2), human ductal carcinoma (MCF-7), human colorectal carcinoma (HCT116), and human lung fibroblast (WI-38) (Figure 10). Free NOR-TENO displayed very strong activity on HepG2 and MCF-7 $\left(I C_{50}=10.68 \pm 1.1\right.$, $9.87 \pm 0.9 \mu \mathrm{g} / \mathrm{ml}$, respectively) and strong cytotoxic effect on HCT116 $\left(I C_{50}=13.69 \pm 1.2 \mu \mathrm{g} / \mathrm{ml}\right)$. NORTENO/microspheres have good MCF-7 killing activity $\left(I C_{50}=21.87 \pm 1.7 \mu \mathrm{g} / \mathrm{ml}\right)$ with moderate HepG2 and HCT116 killing activity $\left(I C_{50}=26.39 \pm 2\right.$, $34.01 \pm 2.3 \mu \mathrm{g} / \mathrm{ml}$, respectively). The cytotoxic effects of NOR-TENO drugs and NOR-TENO/microspheres were tested against normal human cell lines (WI-38). The obtained data displayed that the free NOR-TENO and NOR-TENO/microspheres $\left(I C_{50}=\right.$ $41.86 \pm 3.2,58.12 \pm 3.8 \mu \mathrm{g} / \mathrm{ml}$, respectively) are much less toxic than the control drug DOX $\left(I C_{50}=\right.$ $6.68 \pm 0.5 \mu \mathrm{g} / \mathrm{ml})$, which indicates the selectivity of action towards tumor cells, in addition, a lack of toxicity on normal cells. The NOR-TENO/microspheres showed the desired effects against the tumor cells with a dose lower than the dose of the free drug used, which would reduce the side effects of the free drugs, all this with the minimal impact on the surrounding normal cells. Interestingly, NOR-TENO/microspheres have a good cytotoxic effect on MCF-7 with the lowest toxic effect on normal cells, so, in vivo study was done using MCF-7 tumor cell line.

Lactic acid/glycolic acid (PLGA) electrospun fibers with different ratios of epigallocatechin gallate (EGCG) and camptothecin (CPT) were used for combined colon cancer chemotherapy. Drug release indicated that EGCG and CPT could be released sustainably, while dual-drug-loaded fibers had a higher release rate than single-drug-loaded fibers. These fibers showed clear toxicity against CT26 cells in colon cancer tests, and also, the combination index values of all dual drug-loaded fibers were approximately 0.5 , suggesting a strong synergistic effect of EGCG and CPT [55]. 


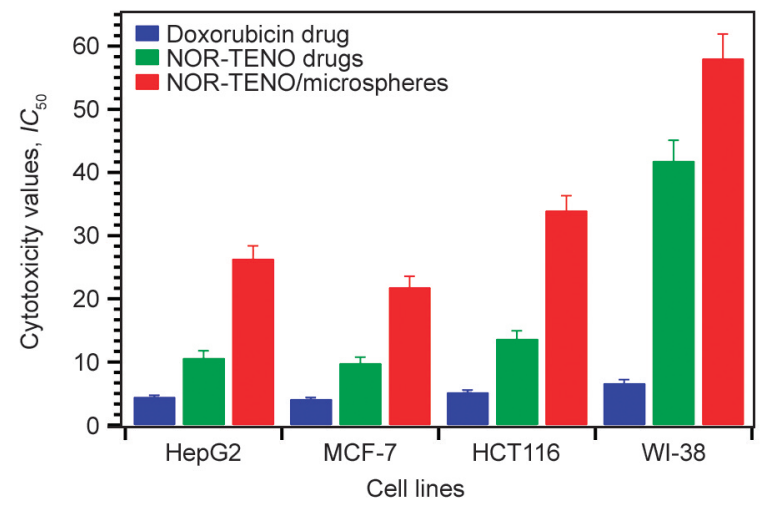

Figure 10. Cytotoxicity assay of compounds against different tumor cell lines and normal cell line.

$I C_{50}[\mu \mathrm{g} / \mathrm{ml}]: 1-10$ (very strong), 11-20 (strong), 21-50 (moderate), 51-100 (weak) and above 100 (non-cytotoxic).

\subsection{Effect of PLA microspheres loaded NOR-TENO drugs on DMBA induced breast cancer in rats}

DMBA was utilized to evaluate the experimental model of chemical carcinogenesis of rat mammary glands. The mammary gland has the ability to activate DMBA, DMBA will be converted into active epoxides and metabolites, thereby destroying the DNA molecules that cause cancer [56].

\subsubsection{Hematological parameters}

The serum hematological parameters in different groups are reported in Table 2. A slight decrease in $\mathrm{Hb}$ level in the group of DMBA compared to the control group, where anemia was developed due to the tumor itself, bone marrow infiltration, blood loss, and nutritional deficiencies. By treating the DMBA group with NOR-TENO/microspheres, Hb level was elevated compared to the group of DMBA, but it didn't achieve the normal value compared with the control group.

There is a clear increase in WBCs in the DMBA group compared to the control group, which may be due to the stress as rats are stress-sensitive. Administration of NOR-TENO/microspheres to the DMBA group reduces elevated WBCs, but it didn't reach the normal value compared to the control group.

Glucose level was increased significantly in the DMBA group as compared to the control group. An independent role of fasting glucose in carcinogenicity has been suggested by various mechanisms ranging from free radical generation to inducing damage to DNA repair enzymes. Increased availability of glucose in the blood may stimulate tumor cells formation, which needs glucose for proliferation [57]. By injection of NOR-TENO/microspheres, Glucose level was reduced, but it did not achieve the normal value compared to the control group.

Lipid profiles parameters as (Total cholesterols and Triglycerols) were significantly increased in the DMBA group [58]; it was reported that elevated total cholesterol was linked with increased breast cancer risk. Buchwald [59] suggests that inhibiting cholesterol by reducing cholesterol availability or reducing intracellular cholesterol synthesis may inhibit tumor cell growth or prevent carcinogenic effects. A high concentration of triacylglycerol will cause the level of SHBG (sex hormone-binding globulin) to decrease, which leads to an increase in the sum of free estradiol, which may raise the risk of breast cancer [60]. Conversely, the treated group showed a significant reduction in total cholesterols and triglycerols compared to the untreated DMBA group.

Table 2. Serum hematological parameters in the different groups under study.

\begin{tabular}{|ll|c|c|c|}
\hline \multirow{2}{*}{\multicolumn{2}{|c|}{ Parameter }} & \multicolumn{3}{c|}{ Animal groups } \\
\cline { 3 - 5 } & \multicolumn{2}{|c|}{ (group I) } & (group II) & $11.14 \pm 0.38^{\mathrm{a}, \mathrm{b}}$ \\
\hline $\mathrm{Hb}$ & {$[\mathrm{g} / \mathrm{dl}]$} & $12.18 \pm 0.32^{\mathrm{a}}$ & $10.18 \pm 0.25^{\mathrm{b}}$ & $8.26 \pm 0.58^{\mathrm{a}, \mathrm{b}}$ \\
\hline $\mathrm{WBCs}$ & {$\left[10^{9} / \mathrm{l}\right]$} & $6.05 \pm 1.18^{\mathrm{b}}$ & $11.41 \pm 1.08^{\mathrm{a}}$ & $92.97 \pm 5.27^{\mathrm{a}, \mathrm{b}}$ \\
\hline Glucose & {$[\mathrm{mg} / \mathrm{d}]$} & $84.73 \pm 3.64^{\mathrm{b}}$ & $106.47 \pm 5.02^{\mathrm{a}}$ & $96.03 \pm 7.71^{\mathrm{a}, \mathrm{b}}$ \\
\hline Total cholesterol & {$[\mathrm{mg} / \mathrm{dl}]$} & $81.1 \pm 4.87^{\mathrm{b}}$ & $115.43 \pm 5.83^{\mathrm{a}}$ & $98.3 \pm 6.72^{\mathrm{b}}$ \\
\hline Triacylglycerol & {$[\mathrm{mg} / \mathrm{dl}]$} & $96.6 \pm 3.70^{\mathrm{b}}$ & $125.47 \pm 6.51^{\mathrm{a}}$ & $39.67 \pm 2.60^{\mathrm{a}, \mathrm{b}}$ \\
\hline ALT & {$[\mathrm{U} / \mathrm{l}]$} & $33.1 \pm 3.00^{\mathrm{b}}$ & $51.00 \pm 5.01^{\mathrm{a}}$ & $100.33 \pm 9.59^{\mathrm{a}, \mathrm{b}}$ \\
\hline AST & {$[\mathrm{U} / \mathrm{l}]$} & $86.00 \pm 4.45^{\mathrm{b}}$ & $135.9 \pm 15.75^{\mathrm{a}}$ & $0.72 \pm 0.05^{\mathrm{b}}$ \\
\hline Creatinine & {$[\mathrm{mg} / \mathrm{dl}]$} & $0.55 \pm 0.06^{\mathrm{b}}$ & $0.96 \pm 0.05^{\mathrm{a}}$ & \\
\hline
\end{tabular}

Data are produced as (Mean \pm S.E.M), S.E.M = Standard error of the mean. Mean values with different superscript letters in the same column are significantly different $(p \leq 0.05)$.

a,bindicated the difference or similarity between experimental groups. 
Creatinine levels showed a significant increase in the DMBA group compared to the control group, where the impairment of the kidney causes the creatinine increase. On the contrary, the treated group showed a substantial reduction in creatinine in comparison with the DMBA group.

The activities of ALT and AST in the DMBA group were significantly increased, and the liver function test mainly depends on the enzymatic levels of alkaline phosphatase, SGOT, and SGPT. Serum glutamate pyruvate transaminase (SGPT) and serum glutamate oxaloacetate transaminase (SGOT) catalyze aspartic acid to oxaloacetate and alanine to pyruvate, respectively. Several studies have shown that these transaminase activities in patients with malignant breast cancer are higher than those in patients with benign breast cancer. Elevated SGOT and SGPT indicate impaired liver and kidney function, which may be related to tumor invasion. Meanwhile, the treated group showed a significant decrease in enzyme activities as compared to the DMBA group.

\subsubsection{Biochemical parameters}

The serum biochemical parameters are reported in Table 3. Nitric oxide (NO) showed an apparent increase in the DMBA group compared to the control group. On the other hand, intraperitoneal injection of NOR-TENO/microspheres to the DMBA group leads to significantly reduced NO level to half, but still twice in the control group.

Nitric oxide or nitric oxide synthase concentrations have been linked to tumor suppression in some cases and tumor progression and metastasis in others [61]. Malondialdehyde (MDA) was statistically more significant in the DMBA group than in the control group; on the contrary, treatment DMBA group with NOR-TENO/microspheres clearly reduced MDA production as compared to the DMBA group. During the

Table 3. Serum biochemical parameters in the different groups under study.

\begin{tabular}{|ll|c|c|c|}
\hline \multirow{2}{*}{ Parameter } & \multicolumn{3}{|c|}{ Animal groups } \\
\cline { 3 - 5 } \multicolumn{2}{|c|}{} & (group I) & (group II) & (group III) \\
\hline NO & {$[\mu \mathrm{mol} / \mathrm{l}]$} & $1.13 \pm 0.08^{\mathrm{c}}$ & $4.07 \pm 0.11^{\mathrm{a}}$ & $2.60 \pm 0.35^{\mathrm{b}}$ \\
\hline MDA & {$[\mu \mathrm{mol} / \mathrm{ml}]$} & $1.28 \pm 0.09^{\mathrm{b}}$ & $1.997 \pm 0.12^{\mathrm{a}}$ & $1.59 \pm 0.099^{\mathrm{b}}$ \\
\hline $\mathrm{SOD}$ & {$[\mathrm{U} / \mathrm{ml}]$} & $21.56 \pm 0.90^{\mathrm{a}}$ & $15.07 \pm 0.66^{\mathrm{b}}$ & $19.95 \pm 0.77^{\mathrm{a}}$ \\
\hline
\end{tabular}

Data are given as $($ Mean \pm S.E.M), S.E.M $=$ Standard error of the mean. Mean values with different superscript letters in the same column are significantly different at $(p \leq 0.05)$.

$a, b, c$ indicated the difference or similarity between experimental groups. carcinogenic process, lipid peroxidation was increased, and a more complex and reactive compound such as Malondialdehyde (MDA) was produced. These lipid peroxidation products have been proven to be mutagenic and carcinogenic. Therefore, it was believed that drugs that can decrease the generation of free radicals in the body have the chemopreventive potential [62].

SOD significantly decreased in the DMBA group as compared to the control group; meanwhile, the DMBA+NOR-TENO/microspheres treated group showed a significant elevation in SOD activity as compared to the DMBA group. Superoxide dismutase (SOD) acts as a mutually supporting antioxidant enzyme and provides protection against reactive oxygen species.

\subsubsection{Histopathological study}

The malignant cell is characterized by acceleration of the cell cycle, genomic alterations; invasive growth; increased cell mobility, and secretion of lytic factors. Morphologically, the cancerous cell is characterized by irregular shape, a large nucleus. The nucleoli are prominent. The cytoplasm is scarce and intensely colored or, on the contrary, is pale [63]. The number of mitoses increases, with defects in the mitotic spindle appearing, resulting in dissymmetrical structures. In addition, apoptosis occurs in the presence of apoptotic bodies. Histological slides of non-lactating mammary glands of Normal, DMBA, and DMBA treated with the drug of female albino rats are shown in Figure 11. Normal mammary gland tissue (group I) contains ducts and lobules dispersed inside animal tissue (Figure 11a). Slides of tumor tissue (group II) showed that, generally, normal ducts and lobules are absent, however, they may fall inside the tumor substrate. An active tumor with varied mitotic divisions within which the nuclei were large and vesicular, were observed. In conjunction with abnormal cells, differentiated and undifferentiated cell types can be seen. The enlargement of vascular structure (arrow) and connective tissue in tumor stroma are noticed (Figure 11a, 11b). Multiple lumina is observed (Figure 11d), which leads to increase cell death, or lumina may be absent (Figure 11e), which indicates breast adenocarcinomas. Necrosis with calcification was diffused in adjacent adipose and muscular tissues, and the neoplastic cells can invade the adipose tissues (Figure 11f, 11g). 
After treatment with NOR-TENO/microspheres (group III), the main pathological change is the vacuolization of tumor cells, with a histocyte-like appearance. The cytoplasm of these cells was large and full of small or interconnected vacuoles (Figure 11h). The immune cells consisted of neutrophils and a high number of lymphocyte and plasmacytoid cells dispersed within the tumor tissue. Treatment with NOR-TENO/microspheres increased the cells infiltration in group III [64]. It was reported that PEGPLA conjugated with a specific peptide F3-loaded paclitaxel nanoparticles (F3-NP-PTX) treated tumors (MCF 7) had extended vacuolation of cancer cells and many other apoptotic cells [64].

\section{Conclusions}

TENO/microspheres were obtained by emulsionevaporation method with TENO encapsulation [\%]
(59.35 $\pm 5.05 \%$ ), followed by NOR loading onto TENO/microspheres surface by direct adsorption technique with loading [\%] (50.08 $\pm 6.38 \%)$. A mixture of NOR-TENO was blended with PLA with loading [\%] (100\% for NOR and TENO); then NORTENO/electrospun fibers were produced by electrospinning process. The release profiles of TENO from microspheres showed sustained release $(22.58,15.33$, and $12.25 \%)$ at $\mathrm{pH}$ values $(7.4,6.7$, and 5.4$)$, respectively, and the release pattern of NOR showed shortterm release $(98.82,91.24$, and $92.92 \%)$ at $\mathrm{pH}$ values (7.4, 6.7 and 5.4), respectively after 20 days. However, in vitro release behavior of TENO from NORTENO/electrospun fibers was slow $(32,24$, and $40 \%)$ at $\mathrm{pH}(5.4,6.7$, and 7.4$)$, respectively. The release of NOR from NOR-TENO/electrospun fibers was rapid $(88,68$, and $100 \%)$ at $\mathrm{pH}(5.4,6.7$, and 7.4$)$, respectively, within 12 days. NOR-TENO/electrospun fibers

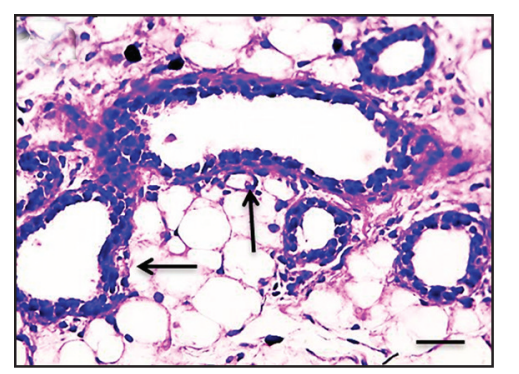

a)

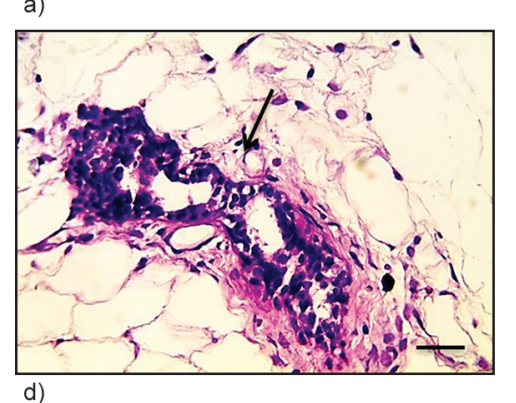

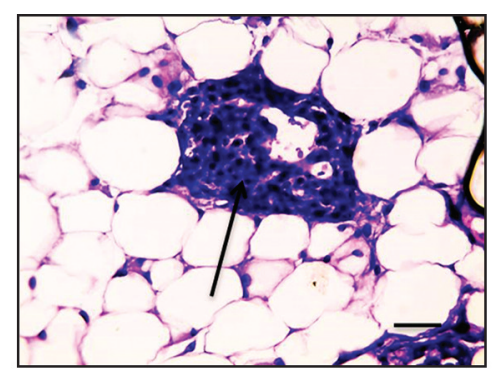

b)

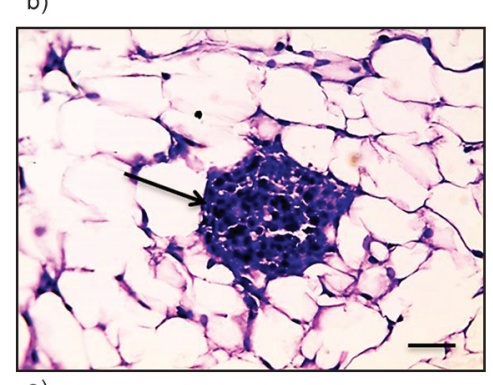

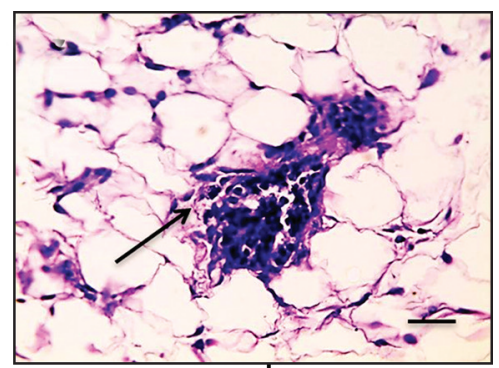

c)

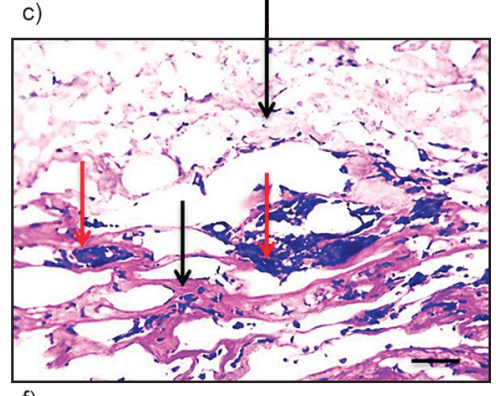

e)
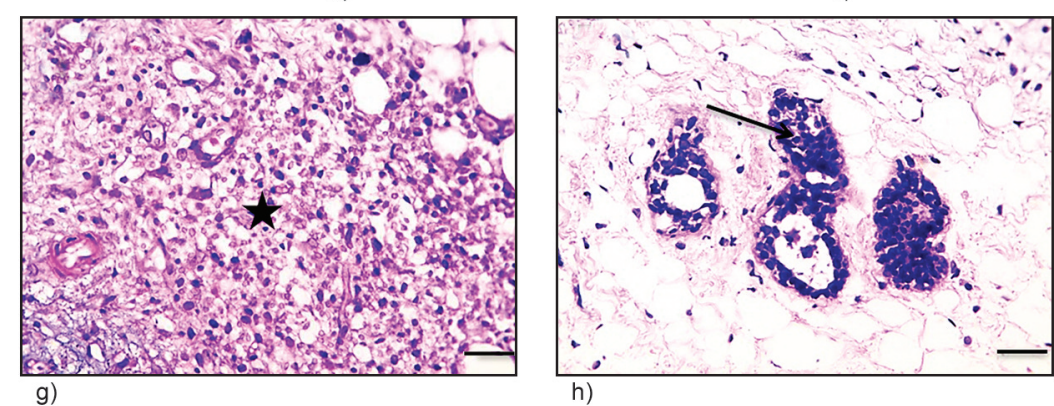

Figure 11. Histological slides of non-lactating mammary glands of female albino rats showing: Normal ductal epithelium (black arrows) in group I (a), ductal carcinoma in situ (DCIS) characterized by enlarged epithelial cells with increased nuclear-cytoplasmic ratio, hyperchromatic nuclei, and single narrowed lumen (black arrow) (b, c), multiple lumina (black arrow) (d) or absent lumen (black arrow) (e), diffuse necrosis (black arrow) with calcification (red arrow) in adjacent adipose and muscular tissues (f) in group II, Invasive DCIS can also be seen (black asterisk) in some fields in group II where neoplastic cells invade the adipose tissue $(\mathrm{g})$, The ductal epithelium shows only ductal hyperplasia (black arrow) with normal surrounding adipose and absent invasive neoplastic cells in group III (h). (Microscopic scale = X: 400 bar 50). 
had better antimicrobial properties against $S$. aureus, E. coli, and B. cereus with inhibition zones $(\sim 52$, 34.66 , and $33.66 \mathrm{~mm}$, respectively than NOR-TENO/ microspheres $(\sim 20.45,26.97$ and $24.27 \mathrm{~mm}$, respectively). In summary, NOR-TENO/ electrospun fibers have a faster release rate (12 days) than NOR-TENO/ microspheres (20 days), but the systems have in common that the release of NOR, TENO was faster at $\mathrm{pH} 7.4$ and that the NOR has a faster release rate than TENO. NOR-TENO/electrospun fibers have excellent antibacterial properties over NOR-TENO/ microspheres and free drugs. This may be related to a relatively high amount of NOR in fiber and faster release in the fibers system. NOR-TENO/microspheres has good efficacy in killing MCF-7 tumor cells $\left(I C_{50} \sim 21.87 \mu \mathrm{g} / \mathrm{ml}\right)$ with a weak effect on WI-38 normal cells $\left(I C_{50} \sim 58.12 \mu \mathrm{g} / \mathrm{ml}\right)$ and in vivo study on MCF-7 tumor cells shows promising results in cancer treatment while NOR-TENO/electrospun fibers are under investigation.

\section{Acknowledgements}

This research did not receive any specific grant from funding agencies in the public, commercial, or not-for-profit sectors.

\section{References}

[1] Liao J., Song Y., Liu C., Li D., Zheng H., Lu B.: Dualdrug delivery based charge-conversional polymeric micelles for enhanced cellular uptake and combination therapy. Polymer Chemistry, 10, 5879-5893 (2019). https://doi.org/10.1039/C9PY01105F

[2] Chierentin L., Salgado H. R. N.: Review of properties and analytical methods for the determination of norfloxacin. Critical Reviews in Analytical Chemistry, 46, 22-39 (2016).

https://doi.org/10.1080/10408347.2014.941456

[3] Sood D., Kumar N., Singh A., Sakharkar M. K., Tomar V., Chandra R.: Antibacterial and pharmacological evaluation of fluoroquinolones: A chemoinformatics approach. Genomics and Informatics, 16, 44-51 (2018). https://doi.org/10.5808/GI.2018.16.3.44

[4] Barman M., Mahmood S., Augustine R., Hasan A., Thomas S., Ghosal K.: Natural halloysite nanotubes/ chitosan based bio-nanocomposite for delivering norfloxacin, an anti-microbial agent in sustained release manner. International Journal of Biological Macromolecules, 162, 1849-1861 (2020).

https://doi.org/10.1016/j.ijbiomac.2020.08.060

[5] Sissi C., Palumbo M.: The quinolone family: From antibacterial to anticancer agents. Current Medicinal Chemistry - Anti-Cancer Agents, 3, 439-450 (2003).

https://doi.org/10.2174/1568011033482279
[6] Yadav V., Talwar P.: Repositioning of fluoroquinolones from antibiotic to anti-cancer agents: An underestimated truth. Biomedicine and Pharmacotherapy, 111, 934946 (2019).

https://doi.org/10.1016/j.biopha.2018.12.119

[7] Salahuddin N., Abdelwahab M., Gaber M., Elneanaey S.: Synthesis and design of norfloxacin drug delivery system based on $\mathrm{PLA} / \mathrm{TiO}_{2}$ nanocomposites: Antibacterial and antitumor activities. Materials Science and Engineering: C, 108, 110337 (2020).

https://doi.org/10.1016/j.msec.2019.110337

[8] Sun S., Cao H., Su H., Tan T.: Preparation and characterization of a novel injectable in situ cross-linked hydrogel. Polymer Bulletin, 62, 699-711 (2009).

https://doi.org/10.1007/s00289-009-0048-9

[9] Ozgocmen S., Ardicoglu O., Erdogan H., Fadillioglu E., Gudul H.: In vivo effect of celecoxib and tenoxicam on oxidant/anti-oxidant status of patients with knee osteoarthritis. Annals of Clinical and Laboratory Science, 35, 137-143 (2005).

[10] Vagare R. S.: Microbial triggered colon targeted compression coated tablets of tenoxicam: Formulation and evaluation. Journal of Drug Delivery and Therapeutics, 5, 75-81 (2015).

https://doi.org/10.22270/jddt.v5i1.1051

[11] Roy S., Banerjee R., Sarkar M.: Direct binding of $\mathrm{Cu}$ (II)-complexes of oxicam NSAIDs with DNA backbone. Journal of Inorganic Biochemistry, 100, 13201331 (2006).

https://doi.org/10.1016/j.jinorgbio.2006.03.006

[12] Knottenbelt C., Chambers G., Gault E., Argyle D. J.: The in vitro effects of piroxicam and meloxicam on canine cell lines. Journal of Small Animal Practice, 47, 14-20 (2006).

https://doi.org/10.1111/j.1748-5827.2006.00006.x

[13] Tamasi G., Casolaro M., Magnani A., Sega A., Chiasserini L., Messori L., Gabbiani C., Valiahdi S. M., Jakupec M. A., Keppler B. K., Hursthouse M. B., Cini R.: New platinum-oxicam complexes as anti-cancer drugs. Synthesis, characterization, release studies from smart hydrogels, evaluation of reactivity with selected proteins and cytotoxic activity in vitro. Journal of Inorganic Biochemistry, 104, 799-814 (2010).

https://doi.org/10.1016/j.jinorgbio.2010.03.010

[14] Cheng J., Teply B. A., Sherifi I., Sung J., Luther G., Gu F. X., Levy-Nissenbaum E., Radovic-Moreno A. F., Langer R., Farokhzad O. C.: Formulation of functionalized PLGA-PEG nanoparticles for in vivo targeted drug delivery. Biomaterials, 28, 869-876 (2007).

https://doi.org/10.1016/j.biomaterials.2006.09.047

[15] Kwon G. S., Furgeson D. Y.: Biodegradable polymers for drug delivery systems. in 'Biomedical polymers' (eds.: Jenkins M.) Woodhead, Cambridge, 83-110 (2007). https://doi.org/10.1533/9781845693640.83 
[16] Kotwal V. B., Saifee M., Inamdar N., Bhise K.: Biodegradable polymers: Which, when and why? Indian Journal of Pharmaceutical Sciences, 69, 616-625 (2007). https://doi.org/10.4103/0250-474X.38465

[17] Li J., Ding J., Liu T., Liu J. F., Yan L., Chen X.: Poly (lactic acid) controlled drug delivery. in 'Industrial applications of poly(lactic acid)' (eds.: Di Lorenzo M. L., Androsch R.) Springer, Switzerland, 109-138 (2017).

[18] Shi X-D., Sun P-J., Gan Z-H.: Preparation of porous polylactide microspheres and their application in tissue engineering. Chinese Journal of Polymer Science, 36, 712-719 (2018). https://doi.org/10.1007/s10118-018-2079-x

[19] Cao T., Gao X., Gu Y.: Biodegradable polylactide microspheres containing anticancer drugs used as injectable drug delivery system. in 'IEEE/ICME International Conference on Complex Medical Engineering. Beijing, China' 226-229 (2007).

[20] Deepika M. S., Thangam R., Sheena T. S., Vimala R. T. V., Sivasubramanian S., Jeganathan K., Thirumurugan R.: Dual drug loaded PLGA nanospheres for synergistic efficacy in breast cancer therapy. Materials Science and Engineering: C, 103, 109716-109734 (2019). https://doi.org/10.1016/j.msec.2019.05.001

[21] Liang Q., Song X., She S., Wang Z., Wang C., Jiang D.: Development of dual delivery antituberculotic system containing rifapentine microspheres and adipose stem cells seeded in hydroxyapatite/tricalcium phosphate. Drug Design, Development and Therapy, 13, 373-384 (2019).

https://doi.org/10.2147/DDDT.S190696

[22] Kanmaz D., Toprakci H. A. K., Olmez H., Toprakçi O.: electrospun polylactic acid based nanofibers for biomedical applications. Material Science Research India, 15, 224-240 (2018).

https://doi.org/10.13005/msri/150304

[23] Poursorkhabi V., Abdelwahab M. A., Misra M., Khalil H., Gharabaghi B., Mohanty A. K.: Processing, carbonization, and characterization of lignin based electrospun carbon fibers: A review. Frontiers in Energy Research, 8, 208-232 (2020).

https://doi.org/10.3389/fenrg.2020.00208

[24] Mao Z., Li J., Huang W., Jiang H., Zimba B. L., Chen L., Wan J., Wu Q.: Preparation of poly(lactic acid)/ graphene oxide nanofiber membranes with different structures by electrospinning for drug delivery. RSC Advances, 8, 16619-16625 (2018). https://doi.org/10.1039/C8RA01565A

[25] Sun C., Zou L., Xu Y., Wang Y.: Ibuprofen-loaded poly(lactic acid) electrospun mats: The morphology, physicochemical performance, and in vitro drug release behavior. Macromolecular Materials and Engineering, 305, 2000457 (2020).

https://doi.org/10.1002/mame.202000457
[26] Pandey S. K., Patel D. K., Thakur R., Mishra D. P., Maiti P., Haldar C.: Anti-cancer evaluation of quercetin embedded PLA nanoparticles synthesized by emulsified nanoprecipitation. International Journal of Biological Macromolecules, 75, 521-529 (2015).

https://doi.org/10.1016/j.ijbiomac.2015.02.011

[27] Dave V., Yadav R. B., Kushwaha K., Yadav S., Sharma S., Agrawal U.: Lipid-polymer hybrid nanoparticles: Development \& statistical optimization of norfloxacin for topical drug delivery system. Bioactive Materials, 2, 269-280 (2017).

https://doi.org/10.1016/j.bioactmat.2017.07.002

[28] Zhu Y., Pyda M., Cebe P.: electrospun fibers of poly(Llactic acid) containing lovastatin with potential applications in drug delivery. Journal of Applied Polymer Science, 134, 45287 (2017).

https://doi.org/10.1002/app.45287

[29] Klančnik A., Piskernik S., Jeršek B., Možina S. S.: Evaluation of diffusion and dilution methods to determine the antibacterial activity of plant extracts. Journal of Microbiological Methods, 81, 121-126 (2010).

https://doi.org/10.1016/j.mimet.2010.02.004

[30] Fadda A. A., Berghot M. A., Amer F. A., Badawy D. S., Bayoumy N. M.: Synthesis and antioxidant and antitumor activity of novel pyridine, chromene, thiophene and thiazole derivatives. Archiv der Pharmazie, 345, 378-385 (2012).

https://doi.org/10.1002/ardp.201100335

[31] Sahragard A., Alavi Z., Abolhassanzadeh Z., Moein M., Mohammadi-Bardbori A., Omidi M., Zarshenas M. M.: Assessment of the cytotoxic activity of triphala: A semisolid traditional formulation on $\mathrm{HEPG}_{2}$ cancer cell line. BioMed Research International, 2021, 6689568 (2021). https://doi.org/10.1155/2021/6689568

[32] Arroyo-Acevedo J., Chávez-Asmat R. J., AnampaGuzmán A., Donaires R., Ráez-Gonzáles J.: Protective effect of piper aduncum capsule on DMBA-induced breast cancer in rats. Breast Cancer: Basic and Clinical Research, 9, 41-48 (2015).

https://doi.org/10.4137/BCBCR.S24420

[33] Zonios G., Bykowski J., Kollias N.: Skin melanin, hemoglobin, and light scattering properties can be quantitatively assessed in vivo using diffuse reflectance spectroscopy. Journal of Investigative Dermatology, 117, 1452-1459 (2001).

https://doi.org/10.1046/j.0022-202x.2001.01577.x

[34] Yoon H., Xuan X., Jeong S., Park J. Y.: Wearable, robust, non-enzymatic continuous glucose monitoring system and its in vivo investigation. Biosensors and Bioelectronics, 117, 267-275 (2018).

https://doi.org/10.1016/j.bios.2018.06.008

[35] Jasprica I., Mornar A., Debeljak Ž., Smolčić-Bubalo A., Medić-Šarić M., Mayer L., Romić Ž., Bućan K., Balog T., Sobočanec S., Šverko V.: In vivo study of propolis supplementation effects on antioxidative status and red blood cells. Journal of Ethnopharmacology, 110, 548554 (2007).

https://doi.org/10.1016/j.jep.2006.10.023 
[36] Christiadi D., Erlich J., Levy M., Herath S., Qian J., Boardman S., Campbell C., Kotwal S., Horvath A. R., Endre Z.: The kinetic estimated glomerular filtration rate ratio predicts acute kidney injury. Nephrology, 26, 782-789 (2021).

https://doi.org/10.1111/nep. 13918

[37] Ufelle S., Onyekwelu K., Chinweoke A., Ibegbu D., Okoli U., Ikekpeazu J.: Assessment of hepatic functions, hematopoietic cytokines and haematological parameters in people occupationally exposed to volatile petroleum hydrocarbons. Archives of Environmental and Occupational Health, 1-5 (2020). https://doi.org/10.1080/19338244.2020.1832037

[38] Alexandre J., Nicco C., Chéreau C., Laurent A., Weill B., Goldwasser F., Batteux F.: Improvement of the therapeutic index of anticancer drugs by the superoxide dismutase mimic mangafodipir. Journal of the National Cancer Institute, 98, 236-244 (2006).

https://doi.org/10.1093/jnci/djj049

[39] Wood L. G., Gibson P. G., Garg M. L.: A review of the methodology for assessing in vivo antioxidant capacity. Journal of the Science of Food and Agriculture, 86, 2057-2066 (2006). https://doi.org/10.1002/jsfa.2604

[40] Goshi E., Zhou G., He Q.: Nitric oxide detection methods in vitro and in vivo. Medical Gas Research, 9, 192207 (2019). https://doi.org/10.4103/2045-9912.273957

[41] Salahuddin N., Gaber M., Elneanaey S., Snowdon M. R., Abdelwahab M. A.: Co-delivery of norfloxacin and tenoxicam in $\mathrm{Ag}-\mathrm{TiO}_{2} /$ poly(lactic acid) nanohybrid. International Journal of Biological Macromolecules, 180, 771-781 (2021).

https://doi.org/10.1016/j.ijbiomac.2021.03.033

[42] Aytac Z., Kusku S. I., Durgun E., Uyar T.: Encapsulation of gallic acid/cyclodextrin inclusion complex in electrospun polylactic acid nanofibers: Release behavior and antioxidant activity of gallic acid. Materials Science and Engineering: C, 63, 231-239 (2016). https://doi.org/10.1016/j.msec.2016.02.063

[43] Saritha A., Shastri N. R.: Preparation, physico chemical characterization of solid dispersions of tenoxicam with poloxamer. Journal of Pharmaceutical Science and Technology, 2, 308-311 (2010).

[44] Carrasco F., Pagès P., Gámez-Pérez J., Santana O. O., Maspoch M. L.: Processing of poly(lactic acid): Characterization of chemical structure, thermal stability and mechanical properties. Polymer Degradation and Stability, 95, 116-125 (2010).

https://doi.org/10.1016/j.polymdegradstab.2009.11.045

[45] Fan T., Daniels R.: Preparation and characterization of electrospun polylactic acid (PLA) fiber loaded with birch bark triterpene extract for wound dressing. AAPS PharmSciTech, 22, 205 (2021).

https://doi.org/10.1208/s12249-021-02081-Z
[46] Wang F., Sun Z., Yin J., Xu L.: Preparation, characterization and properties of porous PLA/PEG/curcumin composite nanofibers for antibacterial application. Nanomaterials, 9, 508-522 (2019).

https://doi.org/10.3390/nano9040508

[47] Cohen S., Yoshioka T., Lucarelli M., Hwang L. H., Langer R.: Controlled delivery systems for proteins based on poly(lactic/glycolic acid) microspheres. Pharmaceutical Research, 8, 713-720 (1991).

https://doi.org/10.1023/A:1015841715384

[48] Moritera T., Ogura Y., Honda Y., Wada R., Hyon S. H., Ikada Y.: microspheres of biodegradable polymers as a drug-delivery system in the vitreous. Investigative Ophthalmology and Visual Science, 32, 1785-790 (1991).

[49] Ford Versypt A. N., Pack D. W., Braatz R. D.: Mathematical modeling of drug delivery from autocatalytically degradable PLGA microspheres - A review. Journal of Controlled Release, 165, 29-37 (2013).

https://doi.org/10.1016/j.jconrel.2012.10.015

[50] Lizambard M., Menu T., Fossart M., Bassand C., Agossa K., Huck O., Neut C., Siepmann F.: In-situ forming implants for the treatment of periodontal diseases: Simultaneous controlled release of an antiseptic and an anti-inflammatory drug. International Journal of Pharmaceutics, 572, 118833 (2019).

https://doi.org/10.1016/j.ijpharm.2019.118833

[51] Sun M., Zhu C., Long J., Lu C., Pan X., Wu C.: PLGA microsphere-based composite hydrogel for dual delivery of ciprofloxacin and ginsenoside RH2 to treat Staphylococcus aureus-induced skin infections. Drug Delivery, 27, 632-641 (2020).

https://doi.org/10.1080/10717544.2020.1756985

[52] Budai-Szűcs M., Léber A., Cui L., Józó M., Vályi P., Burián K., Kirschweng B., Csányi E., Pukánszky B.: electrospun PLA fibers containing metronidazole for periodontal disease. Drug Design, Development and Therapy, 14, 233-242 (2020).

https://doi.org/10.2147/DDDT.S231748

[53] Dalmolin L. F., Khalil N. M., Mainardes R. M.: Delivery of vanillin by poly(lactic-acid) nanoparticles: Development, characterization and in vitro evaluation of antioxidant activity. Materials Science and Engineering: C, 62, 1-8 (2016).

https://doi.org/10.1016/j.msec.2016.01.031

[54] Gupta V. K., Sood S., Agarwal S., Saini A. K., Pathania D.: Antioxidant activity and controlled drug delivery potential of tragacanth gum-cl-poly(lactic acid-co-itaconic acid) hydrogel. International Journal of Biological Macromolecules, 107, 2534-2543 (2018).

https://doi.org/10.1016/j.ijbiomac.2017.10.138

[55] Duan L., Yang X., Ma Y., Wu J., Zou Y., Xiao B., Yi S.: Dual epigallocatechin gallate and camptothecin loaded electrospun meshes for synergy combination chemotherapy of colon cancer. Journal of Applied Polymer Science, 138, 50983 (2021). https://doi.org/10.1002/app.50983 
[56] Barros A. C., Muranaka E. N., Mori L. J., Pelizon C. H., Iriya K., Giocondo G., Pinotti J. A.: Induction of experimental mammary carcinogenesis in rats with 7,12dimethylbenz(a)anthracene. Revista do Hospital das Clínicas, 59, 257-261 (2004).

https://doi.org/10.1590/S0041-87812004000500006

[57] de Araújo L. B. N., Cal B. B. F., Nunes B. M., da Cruz L. O. D., da Silva C. R. D., de Castro T. C., Leitão Á C., de Pádula M., Albarello N., Dantas F. J. S.: Nuclear and mitochondrial genome instability induced by fractions of ethanolic extract from hovenia dulcis thunberg in saccharomyces cerevisiae strains. Anais da Academia Brasileira de Ciências, 93, e20191436 (2021). https://doi.org/10.1590/0001-3765202120191436

[58] Yadav N. K., Poudel B., Thanpari C., Koner B. C.: Assessment of biochemical profiles in premenopausal and postmenopausal women with breast cancer. Asian Pacific Journal of Cancer Prevention, 13, 3385-3388 (2012).

https://doi.org/10.7314/APJCP.2012.13.7.3385

[59] Buchwald H.: Cholesterol inhibition, cancer, and chemotherapy. The Lancet, 339, 1154-1160 (1992). https://doi.org/10.1016/0140-6736(92)90744-N
[60] Alnowihi S. M., Al Doghaither H. A., Osman N. N. Serum visfatin concentration and its relationship with sex hormones in obese Saudi women. International Journal of Health Sciences, 14, 9-13 (2020).

[61] Hickok R. J., Thomas D. D.: Nitric oxide and cancer therapy: The emperor has no clothes. Current Pharmaceutical Design, 16, 381-391 (2010).

https://doi.org/10.2174/138161210790232149

[62] Li Y., Zhang S., Jiang W., Liu D.: Cadmium accumulation, activities of antioxidant enzymes, and malondialdehyde (MDA) content in Pistia stratiotes L. Environmental Science and Pollution Research, 20, 11171123 (2013).

https://doi.org/10.1007/s11356-012-1054-2

[63] Baba A. I., Câtoi C.: Tumor cell morphology. in 'Comparative oncology' (eds.: Baba A. I., Câtoi C.) The Publishing House of the Romanian Academy, Bucharest, 36-67 (2007).

[64] Cai Y., Xu Z., Shuai Q., Zhu F., Xu J., Gao X., Sun X.: Tumor-targeting peptide functionalized PEG-PLA micelles for efficient drug delivery. Biomaterials Science, 8, 2274-2282 (2020). https://doi.org/10.1039/C9BM02036E 